\title{
Experimental verification of the percussive drilling model
}

\author{
Maolin Liao ${ }^{\mathrm{a}, \mathrm{b}}$, Marian Wiercigroch ${ }^{\mathrm{b}}$, Mukthar Sayah $^{\mathrm{b}}$, James Ing ${ }^{\mathrm{b}}$ \\ ${ }^{a}$ School of Mechanical Engineering, University of Science and Technology Beijing, 100083, China \\ ${ }^{b}$ Centre for Applied Dynamics Research, School of Engineering, University of Aberdeen, Aberdeen AB24 $3 U E$, UK
}

\begin{abstract}
This paper focuses on the experimental verification of a dynamical model describing percussive drilling. The design of the experimental apparatus is introduced firstly, and then the dynamic interactions between rock and indenter are studied experimentally by varying three control parameters, including frequency and amplitude of excitation, and pneumatic pressure applied on the indenter. Additionally, the influence of rock stiffness is analyzed by testing different rock-indenter combinations. Meanwhile, the corresponding numerical simulations were conducted showing good agreements with the experimental results. According to the detailed bifurcation analyses, the dynamic responses of indenter mainly display period-one motions which can further develop into period-two motions via period-doubling bifurcation scenarios, or even chaotic motions by period-doubling cascade. The chaotic vibration of indenter can also return to periodic motions via inverse period-doubling bifurcation or fold bifurcation. Although the period-one motion is the main dynamic response in the considered parameter ranges, its impact number per excitation period varies with parameters, which directly affects the maximal impact acceleration of indenter. This results in more energy being dissipated during repeated weak impacts. Therefore, strong impacts are obtained if the indenter is exhibiting the period-one with one-impact motion. For such a purpose, high excitation frequency and amplitude are suggested, however, the high pneumatic pressure should be avoided since it can trigger chattering of the indenter.
\end{abstract}

Keywords: Nonlinear dynamical system; Percussive drilling; Bit-rock interactions; Bifurcation analysis;Experimental studies

Email addresses: liaomaolin@ustb.edu.cn (Maolin Liao), m.wiercigroch@abdn.ac.uk (Marian Wiercigroch), m.sayah@abdn.ac.uk (Mukthar Sayah), j.ing@abdn.ac.uk (James Ing) 


\section{Introduction}

In petroleum industry, a significant expenditure is made in drilling departments for constructing wells to explore oil and gas reservoirs. Cost of well drilling is generally charged by days, or even by hours for offshore drilling; hence, drilling efficiency is always a key index for its cost control. Two basic drilling modes were ever used, i.e., percussive drilling and rotary drilling. Currently, rotary drilling is in an absolute dominant position in petroleum industry since it replaced percussive drilling about 200 years ago, and the main reason comes from its higher drilling efficiency, which relies on the blades cutting or teeth grinding of drill bits driven by rotation torque. However, as the increase of well depth, the drilled rocks are hardened by increasing overburden pressure; under such circumstances, the rotary drilling generally shows a sharp decrease in drilling efficiency, since neither the blades cutting nor the teeth grinding can break hard rocks with high efficiency. Unfortunately, as the petroleum resources stored in shallow layers have been fully exploited, the deep or super-deep well drilling becomes inevitable nowadays; therefore, the percussive drilling returns to public eyes again, since its basic advantage is to provide powerful axial impact force to fragment hard rocks.

Certainly, the pure percussive drilling is still not efficient enough for drilling hard rocks; however, if it is combined with the rotary drilling, both of their advantages are expected to be complementary. Specifically, the percussion of drill bit takes the responsibility of crushing hard rock primarily, and then the cutting or grinding motion helps bit drills pass through the crashed zone and remove the fragments; hence the whole drilling efficiency can be promoted effectively. Such a combined drilling mode is named as rotary-percussive drilling. National Oilwell Varco company ever conducted a field test in West Africa for drilling stiff formation whose compressive strength was 20 30kpsi [1]. According to their field measurements, when the bit percussion was added to the conventional rotary drilling, the measured rate of penetration (ROP) was almost doubled. This case demonstrated the great potential of rotary-percussive drilling in drilling hard rocks, which deserves deeper investigations.

In order to apply the rotary-percussive drilling, the understandings of both the rotary motion and the percussive motion of drill bit are the preconditions. Since a great number of investigations have discussed the working principles of the rotary drilling comprehensively; in this paper, the dynamics of percussive 
drilling will be emphatically studied. Preliminary studies on percussive drilling dates back to the 1970s, Hustrulid and Fairhurst investigated the basic dynamics of a percussive drilling system [2], they proposed a force-penetration correlation for rock deformation under successive impacts [3], and further verified it by corresponding experiments $[4,5]$. Then, the energy exchange mechanism during the percussive destruction of rock was studied by Lundberg [6-8]. According to his experimental investigations, the maximum energy exchange rate from drill bit to rock could approximate $80 \%$ of the total impact energy. From these early researches to know, the physical model of percussive drilling can be divided on two parts, i.e., vibro-impact part and rock deformation part, and the main target is to achieve the highest energy transfer rate from axial impacts, and thus obtain the maximal ROP. Based on such understandings, scholars tried different ways. A high frequency hydraulic hammer with low flow rate was designed by Kiselev and Melamed $[9,10]$. A resonance hammer drilling tool was presented by Franca and Weber [11], and they simulated the forward motion of drill bit by introducing drift into their mathematical model. Neumann and Sattel [12] applied a resonantly driven piezoelectric actuator to excite drill stem, and the periodic, non-periodic, and even chaotic vibrations of drill stem were explored by the set-oriented numerical analysis. Similarly, Potthast et al. [13] tested a piezoelectrically driven vibro-impact drilling tool experimentally, and both a finite element model and a discrete lumped parameter model were developed to reproduce the system dynamics observed in experiments. From the perspective of the self-excited axial vibration, Kovalyshen [14] carried out both the numerical simulation and experiments to test the influence of bit percussion on drilling efficiency. Recently, in order to further promote the penetration rate, the optimization design about drill bit diameter, rotation speed and air pressure for rotary percussive drilling was carried out by Derdour et al. [15], in which both the Taguchi analysis and response surface methodology were applied and were further verified by experiments. While, in order to determine the optimal drilling parameters when considering the dynamical interaction between drill bit and high-temperature granite, Ji et al. [16] improved the drifting oscillator model by introduce an Abel damper to describe the nonlinear relationship between the damping force and strain rate.

On the other aspects, to better describe the rock deformation under bit percussion, Franca [17] proposed a bit-rock interaction model for analysis of dynamics of rotary-percussive drilling. Han et al. 
[18] developed a rock failure model based on finite element method, and carried out experimental tests to further improve the proposed model $[19,20]$. Dong and Chen [21] established a model to describe the rotary percussive drilling with a full-scale polycrystalline diamond compact (PDC) bit, and they focused on the dynamic damage characteristics of anisotropic shale, and verified that rock element damage occurs along the direction of maximum principal stress. In addition, Ritto et al [22] developed a hysteretic bitrock interaction model, and they discussed the influences of bit-rock interaction on the torsional dynamics of drill string, and thus the stability region of the drill string system was effectively determined. Moreover, Ritto et al [23] further proposed a stochastic model to describe the uncertainties on the rock strength, and they also took the bit dynamics into consideration; by this way, the worst case for the severer vibration of bit was presented.

In addition to the aforementioned research, during the past twenty years, for the purpose of developing new resonance enhanced drilling (RED) techniques and equipment [24-26], scholars from University of Aberdeen focused on the nonlinear dynamics of percussive drilling systems [27]. Primarily, for describing the vibro-impact motion of the percussive drilling, a low-dimensional drifting oscillator was introduced in [28] to qualitatively simulate the dynamics of the percussive drilling, based on which, bifurcation scenarios of the low-dimensional model were analyzed [29], and the vibrations of oscillator under the kinematic excitation with a beat frequency were discussed [30]. In order to eliminate the influence of drift on the analysis of dynamics of percussive drilling systems, the original co-ordinates were decoupled, and thus the bounded oscillation was separated from its drift [31, 32]. Based on the decoupled models, the numerical continuation of the drifting oscillator has been conducted [33] by using a computational package TCHAT [34]. Thereafter, high frequency vibro-impact models with various degree of freedom (DOF) were compared [35], and the numerical simulations demonstrated that the period-one one-impact motion for the axial vibration of drill bit displayed the highest ROP, and thus the corresponding control strategy was investigated [36]. For developing the deformation model of rock under percussive drilling, a series of quasi-static rock indentation tests were conducted to observe the correlation between impact force and the indentation on the rock surface [37-40]. Based on the experimental results, two regimes during the bit-rock interactions were identified, i.e., loading phase and the unloading phase. Specifically, in a 
loading phase, a part of the input kinetic energy was dissipated due to friction, and the rest was stored as elastic strain energy; when the corresponding unloading phase began, the stored elastic strain energy was released to recover a part of the indentation of rock, and thus a certain penetration was achieved. Under such circumstances, the total energy dissipation can be reflected indirectly by the difference between the loading and unloading stiffness coefficients. Based on the aforementioned researches, in order to verify the theoretical and numerical analyses, an experimental rig for percussive drilling systems has been built up in University of Aberdeen [41], and a series of experimental tests were thus carried out.

This paper follows the previous research routing of University of Aberdeen, and further verify the dynamics explored by the proposed percussive drilling model [42] via the built experimental apparatus [41]. Therefore, the rest parts of this paper are organized as follows. In Section 2, the experimental apparatus is introduced, and parameter identification of this experimental rig is presented. Then the experimental measurements and the influence of rock rotation are discussed. In the next section, the mathematical model of the percussive drilling system is briefly introduced, and its basic dynamics is discussed in detail. In Section 4, the experimental investigations for dynamic responses of percussive drilling systems are carried out by sweeping three control parameters and testing different rock-indenter combinations, and the agreements between the numerical simulations and the experimental results are verified. Finally, concluding remarks are drawn in the last section.

\section{Experimental apparatus and parameter identification}

This section mainly introduces the experimental apparatus which was designed for performing highfrequency vibro-impacts, and the corresponding system parameters for both the vibro-impact model and the rock deformation model are identified. Subsequently, based on the collected acceleration signal of indenter, the influence of rock rotation on the axial vibration of indenter is discussed.

\subsection{Experimental apparatus}

The experimental apparatus was developed by the Centre of Applied Dynamic Research (CADR) in University of Aberdeen. As shown in Fig. 2.1, this experimental apparatus consists of a measurement 
system (see subplot (a)) and an experimental rig (see subplot (b)). As can be observed in Fig. 2.1 (b), both an excited indenter and an impacted medium are installed horizontally and co-axially. The axial vibration is provided to the indenter via an electro-dynamic shaker. While the pneumatic pressure is applied to the indenter by using a pneumatic cylinder, whose pressure is adjusted via a control valve attached to the air hose which determines the supply of the compressed air. In particular, to simplify the structure of the experimental rig, the rock instead of the indenter was designed to rotate; hence, an electrical DC motor and a set of pulleys are used to rotate the impacted rock. Once only the percussive drilling is considered, this part of components will not be activated. The experimental rig can be grouped as a piston-shaker-indenter combination on the right side and a motor-pulley-rock part on the left side.

During the experiment, the piston-shaker-indenter combination is pushed by the pneumatic cylinder towards the left until the indenter contacting with the rock fixed in the motor-pulley-rock part, then the rock-indenter interaction can be started by exciting the shaker. In particular, to eliminate the influence of the dynamical friction due to the vibration of the shaker, the shaker is fixed in a customized steel frame with four carriages on a pair of parallel guides. Moreover, two pressure regulator discharge and bleeding valves are connected to both sides of the pneumatic cylinder to slow down the piston and thus secure the smooth movement of the shaker.

\subsection{Parameter identification}

Before carrying out experimental tests, a series of system parameters were identified primarily, the obtained results are listed in Table 2.1. On the one hand, four structure parameters were measured for the actuator-shaker-indenter part, including the structure stiffness and structure damping of the shaker, the mass of the shaker body, and the mass of the indenter assembly. In addition, three control parameters can be adjusted in this part, including the excitation amplitude and frequency of the shaker, and the pneumatic pressure provided to the indenter.

On the other hand, the rock deformation process under the impacts of indenter was considered to be described by rock stiffness, which was measured experimentally by using an Instron testing machine, see Fig. 2.2 (a) and (b). Specifically, a rock sample was put on the moving table which was then lifted 

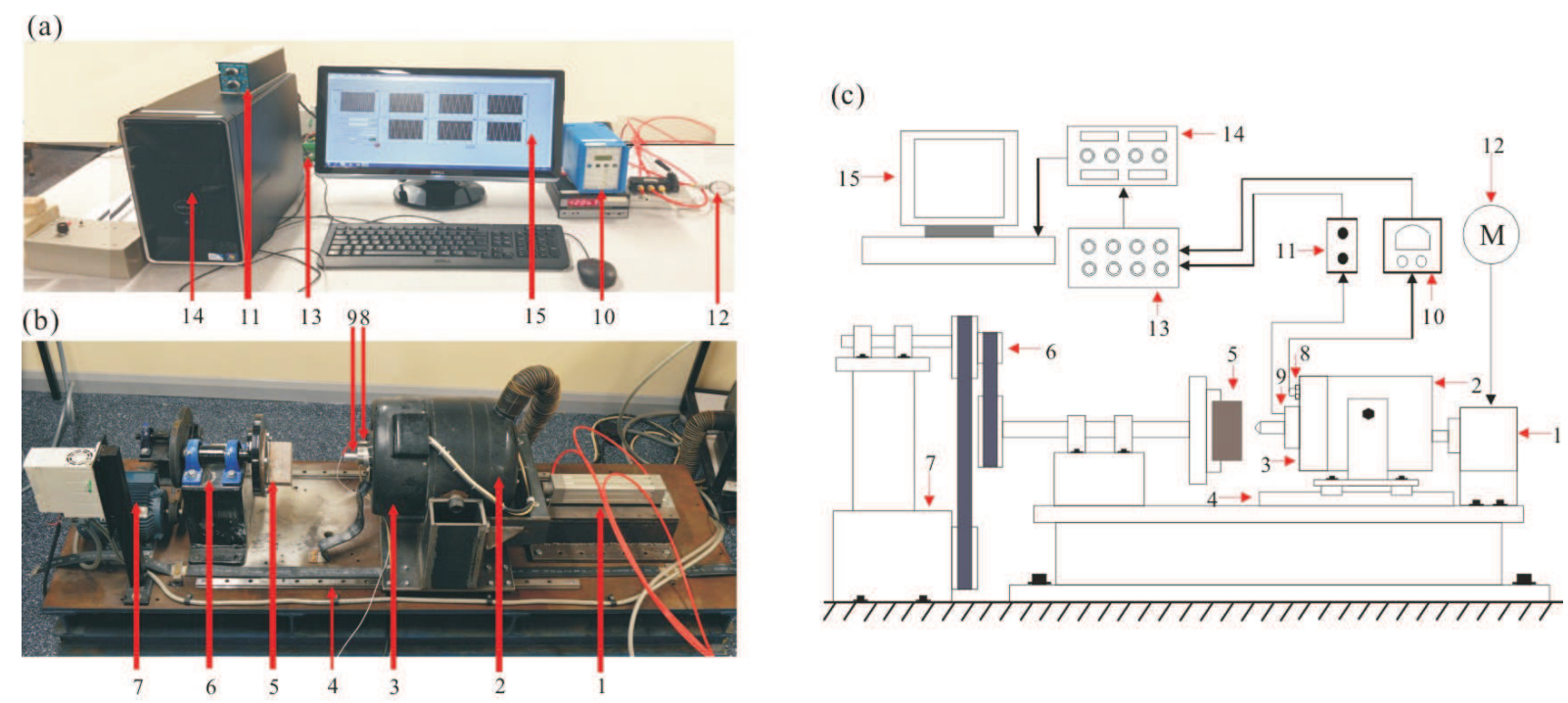

(d)

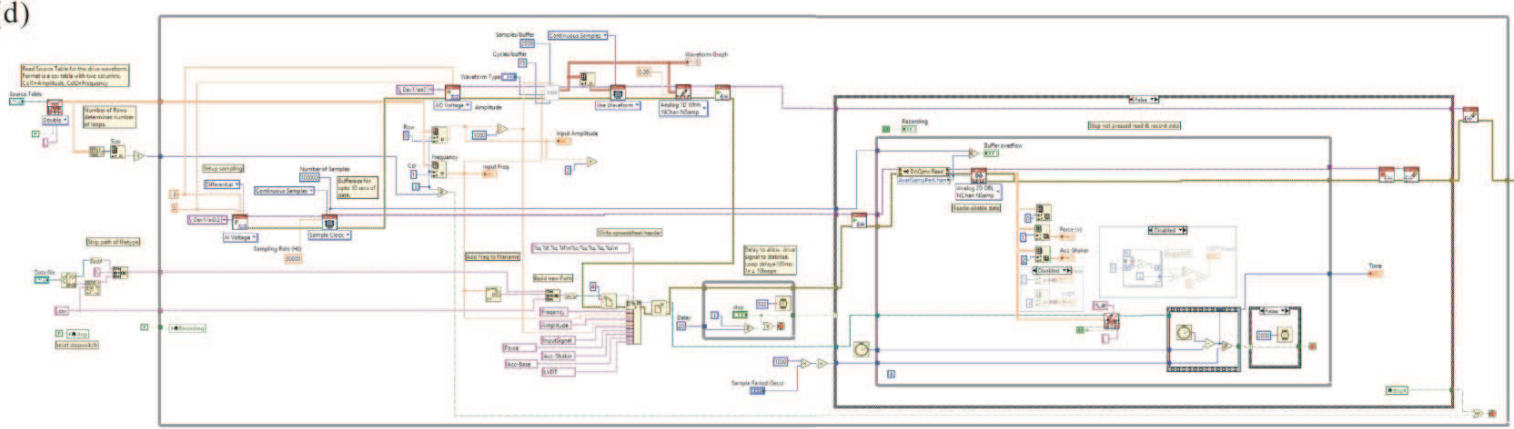

Figure 2.1: Experimental rig of a percussive drilling system, (a) measurement system, (b) experimental rig, (c) schematic of the experimental apparatus, including: 1-pneumatic cylinder, 2-external frame of shaker, 3-electrodynamic shaker, 4-linear guides, 5-impacted rock, 6-pulley block, 7-DC motor, 8-accelerometer, 9-load cell, 10-charge amplifier for accelerometer, 11-charge amplifier for load cell, 12-pressure gauge, 13-I/O connector, 14 and 15 for the controller board installed in PC. Subplot (d) shows the block diagram built in LabVIEW.

until the rock contacting with the indenter installed on the top beam. After that, the table kept moving upwards with a constant speed $0.1 \mathrm{~mm} / \mathrm{min}$, and the indenter was forced to penetrate into the rock. With the increase of indentation, the contact force between the indenter and the rock increased simultaneously, this process is known as a loading phase which was ended when the set maximal loading force was achieved. In this experiment, the maximal loading force was set as $3.0 \mathrm{kN}$ which corresponded to the maximal impact force detected from the following percussive drilling tests, see Fig. 2.4 (b). After the loading phase, the table moved downwards immediately until the contact force returned to zero, and this process is known as an unloading phase. In this experiment, a linear variable differential transformer (LVDT) displacement transducer was used to measure the indentation on the rock; and the contact force 
Table 2.1: System parameters identified from the experimental rig

\begin{tabular}{|c|c|c|}
\hline Parameter & Symbol & Value \\
\hline Structure stiffness & $k$ & $68.85 \mathrm{kN} / \mathrm{m}$ \\
Structure damping & $c$ & $2.45 \mathrm{kN} \cdot \mathrm{s} / \mathrm{m}$ \\
Mass of shaker body & $m_{1}$ & $265 \mathrm{~kg}$ \\
Mass of indenter assembly & $m_{2}$ & $3 \mathrm{~kg}$ \\
Excitation voltage amplitude & $A$ & $300 \sim 600 \mathrm{mV}$ \\
Excitation frequency & $\Omega$ & $50 \sim 120 \mathrm{~Hz}$ \\
Pneumatic pressure & $p$ & $0.6 \sim 1.8 \mathrm{bar}$ \\
Loading stiffness of rock & $k_{l}$ & $11 \sim 33 \mathrm{kN} / \mathrm{mm}$ \\
Unloading stiffness of rock & $k_{u}$ & $13 \sim 41 \mathrm{kN} / \mathrm{mm}$ \\
\hline
\end{tabular}

was measured by a built-in load sensor of the Instron testing machine. These measurements are then linearly fitted to calculate the loading and unloading stiffnesses for the tested rock-indenter combination.

Theoretically, the loading and unloading stiffnesses of a rock-indenter combination are determined by the product of the Young's modulus of the rock $(E)$ and the contact area of the indenter $(A)$, namely, $(E \cdot A)$. Hence, in order to get more stiffness cases, two rock samples with different Young's moduli (sandstone-1 with Young's modulus 4.80 GPa, and sandstone-2 with Young's modulus 28.51 GPa) and three indenters with different contact angles $\left(30^{\circ}, 45^{\circ}\right.$, and $\left.60^{\circ}\right)$ were coupled mutually, see the examples shown in Fig. 2.2 (c) and (d); by this way, totally six rock-indenter combinations were coupled. For each rock-indenter combination, the loading and unloading process for the rock indentation test was repeated ten times to observe the variation of the rock stiffness. The recorded experimental data for the sandstone1-indenter30 combination and the sandstone2-indenter45 combination are depicted in Fig. 2.2 (e) and (f), respectively. As can be seen, the repeated ten tests can be divided into three groups. Specifically, the rock is impacted in the first contact where an obvious indentation is achieved, see the red curves in Fig. 2.2 (e) and (f); then, the rock is compressed during the following four tests where the small indentations can still be observed, see the green curves; finally, both the loading and unloading stiffnesses reached relatively constant in the last five cycles where steep force-penetration curves are obtained, see the blue curves. These observations indicate that, in the first few contacts, both the loading and unloading stiffnesses keep increasing since the rock was compacted gradually under repeated contacts; as more contacts are applied, the loading and unloading stiffnesses keep constant, the rock-indenter interaction 
become stable.

(a)

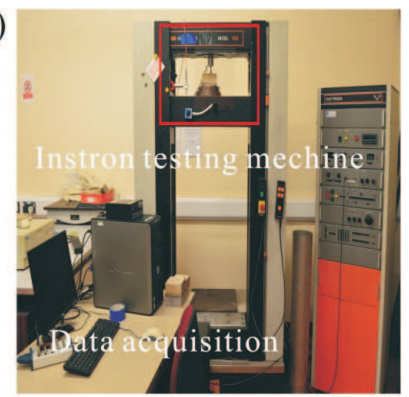

(b)

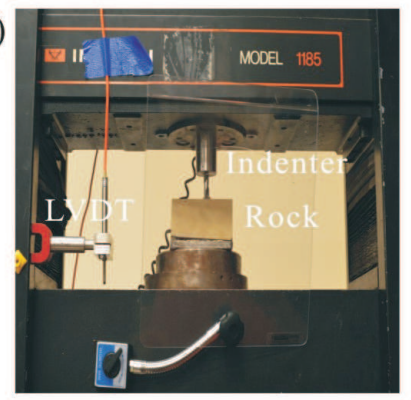

(c)

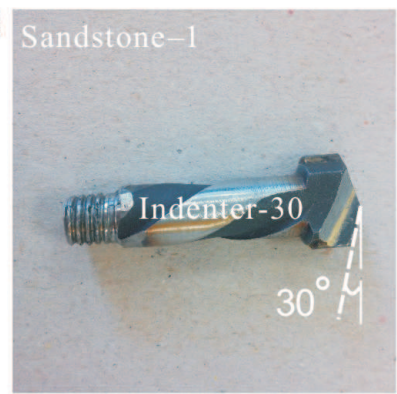

(d)

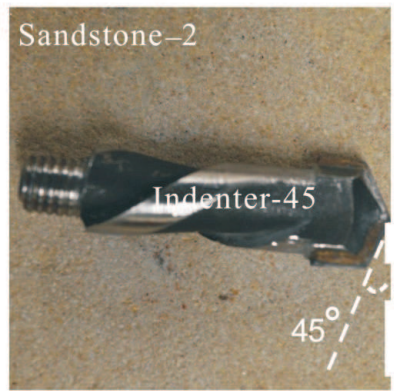

(e)

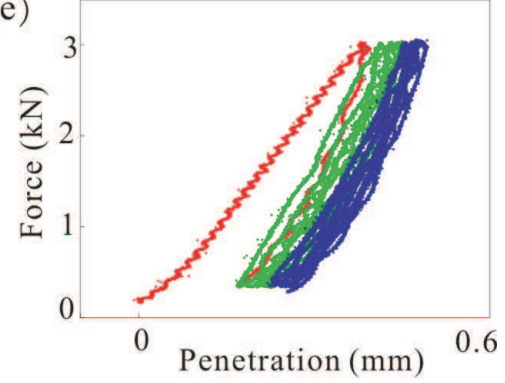

(f)

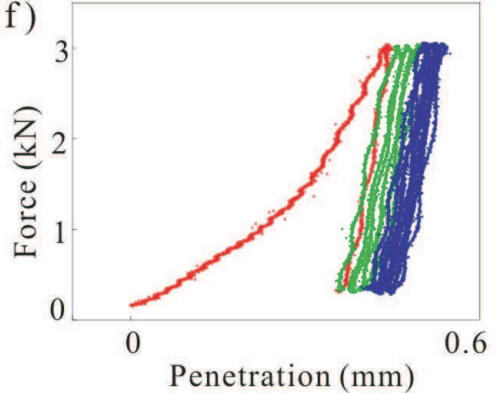

Figure 2.2: Quasi-static rock-indenter interaction test. Subplot (a) shows the experimental setup, which consists of an Instron testing machine and a data acquisition system. Subplot (b) shows the details of the measurement zone which is marked by a red rectangle in subplot (a). Subplot (c) shows the combination of sandstone-1 and indenter-30, and its corresponding experimental measurements are shown in subplot (e). Subplot (d) shows the combination of sandstone-2 and indenter-45, and its corresponding experimental measurements are shown in subplot (f).

Based on the collected experimental data, the force-penetration correlations in both the loading and unloading phases can be fitted. According to the conclusions proposed in [42], when drilling hard rocks, the bifurcation structure of percussive drilling system is qualitatively similar for the linear and nonlinear rock-indenter interaction laws. Namely, when the linear fitting or the nonlinear fitting rock model is applied, the differences of the dynamic responses of such systems are neglected. Therefore, in this paper, the linear fitting is considered since it well fits the main parts of the experimental measurements, and also can effectively promote the computational efficiency for the following numerical simulations introduced in Section 4. For instance, the experimental measurements of the sandstone2-indenter30 combination for its first, third, and tenth tests and their corresponding linear fitting lines are displayed in Fig. 2.3. For the first test, the fitted linear loading stiffness is $k_{l}=5.42 \mathrm{kN} / \mathrm{mm}$ and unloading stiffness is $k_{u}=21.57$ $\mathrm{kN} / \mathrm{mm}$. For the third test, $k_{l}=15.95 \mathrm{kN} / \mathrm{mm}$ and $k_{u}=23.55 \mathrm{kN} / \mathrm{mm}$, respectively. For the tenth test, $k_{l}=21.55 \mathrm{kN} / \mathrm{mm}$ and $k_{u}=25.36 \mathrm{kN} / \mathrm{mm}$, respectively. In the same way, the linearly fitted loading and 
unloading stiffnesses for all the tested six rock-indenter combinations are listed in Table 2.2. In particular, for any rock-indenter combination, the fitted unloading stiffness is larger than the corresponding loading stiffness, and the stiffness difference corresponds to energy dissipation. Specifically, the more energy is dissipated during contacts, the larger difference between the loading and unloading stiffnesses is observed.

As aforementioned, the ten tests for each rock-indenter combination can be divided into three phases, i.e., impact, compression, and stable phases, respectively. For the following percussive drilling tests using the built experimental rig, the tested rocks will be repeatedly impacted by the indenter with high frequency; hence, the stiffness fitted in the stable phase is closer to that of the following percussive drilling. Therefore, the fitted loading and unloading stiffnesses in the stable phase are averaged to describe the rock deformation characteristics under dynamic impacts of indenter.

(a)

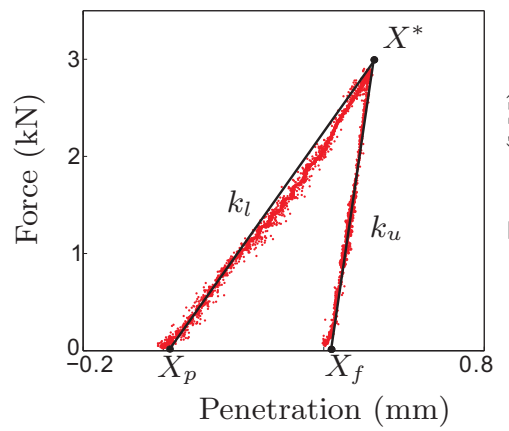

(b)

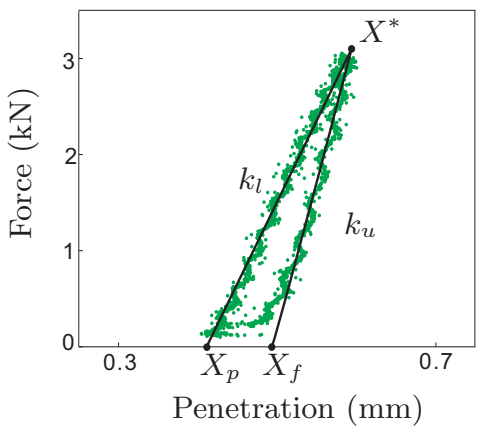

(c)

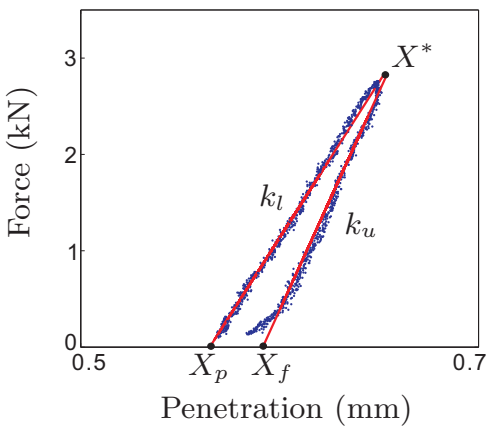

Figure 2.3: Force-penetration correlations for the sandstone2-indenter30 combination. Specifically, the dots are experimental measurements, and the lines show the linear fittings. Subplot (a), (b), (c) show the first, third, and tenth contacts, respectively. In all subplots, $k_{l}$ is the loading stiffness, $k_{u}$ is the unloading stiffness. $X_{p}, X_{f}$, and $X^{*}$ represent the initial position in the loading phase, the ending position in the unloading phase, and the position of the maximal progression, respectively.

\subsection{Experimental measurements}

After the rock-indenter contact test, the indenter and rock were fixed in the experimental rig, as shown in Fig. 2.1 (b), to conduct the percussive drilling tests. As the start, the sandstone2-indenter30 combination was used, the excitation voltage amplitude was set as $500 \mathrm{mV}$, the excitation frequency was set as $100 \mathrm{~Hz}$, and the pneumatic pressure provided to the actuator was set as 1.0 bar. The collected time series are shown in Fig. 2.4, subplot (a) shows the input excitation signal, subplot (b) shows the contact force between the indenter and the rock, and subplot (c) shows the acceleration of the indenter assembly. 
Table 2.2: The fitted linear loading and unloading stiffnesses from experimental data.

\begin{tabular}{|c|c|c|c|c|c|c|}
\hline & \multirow{3}{*}{ Case } & \multirow{3}{*}{ Item } & \multicolumn{4}{|c|}{ Stiffness (kN/mm) } \\
\hline & & & \multirow{2}{*}{ impact } & \multirow{2}{*}{ compression } & \multicolumn{2}{|l|}{ stable } \\
\hline & & & & & measurements & average \\
\hline \multirow{2}{*}{1} & sandstone- 1 & $k_{l}$ & 8.17 & $\begin{array}{l}11.32 ; 11.29 \\
11.62 ; 11.34\end{array}$ & $\begin{array}{c}11.98 ; 11.77 ; 11.73 ; \\
12.43 ; 12.45\end{array}$ & $\begin{array}{l}12.07 \\
\pm 0.35\end{array}$ \\
\hline & indenter-30 & $k_{u}$ & 13.26 & $\begin{array}{l}13.52 ; 13.42 ; \\
13.39 ; 13.71\end{array}$ & $\begin{array}{c}13.89 ; 13.82 ; 14.06 \\
13.60 ; 13.12\end{array}$ & $\begin{array}{l}13.70 \\
\pm 0.37\end{array}$ \\
\hline \multirow{2}{*}{2} & \multirow[t]{2}{*}{ sandstone-1 } & $k_{l}$ & 6.70 & $\begin{array}{l}12.03 ; 11.68 ; \\
11.68 ; 11.92\end{array}$ & $\begin{array}{c}12.10 ; 11.71 ; 11.38 \\
11.98 ; 11.99\end{array}$ & $\begin{array}{l}11.82 \\
\pm 0.25\end{array}$ \\
\hline & & $k_{u}$ & 14.28 & $\begin{array}{l}14.27 ; 13.68 ; \\
14.00 ; 13.99\end{array}$ & $\begin{array}{c}14.17 ; 13.98 ; 13.80 \\
13.83 ; 13.51\end{array}$ & $\begin{array}{l}13.90 \\
\pm 0.21\end{array}$ \\
\hline \multirow{2}{*}{3} & \multirow{2}{*}{$\begin{array}{l}\text { sandstone-1 } \\
\text { indenter-60 }\end{array}$} & $k_{l}$ & 6.47 & $\begin{array}{l}11.01 ; 11.26 ; \\
11.42 ; 12.15 \\
\end{array}$ & $\begin{array}{c}11.55 ; 12.11 ; 11.45 \\
11.67 ; 11.69\end{array}$ & $\begin{array}{l}11.72 \\
\pm 0.30\end{array}$ \\
\hline & & $k_{u}$ & 13.23 & $\begin{array}{l}13.4313 .11 ; \\
12.90 ; 13.43\end{array}$ & $\begin{array}{c}13.70 ; 13.23 ; 13.03 \\
13.95 ; 13.66\end{array}$ & $\begin{array}{l}13.41 \\
\pm 0.38\end{array}$ \\
\hline \multirow{2}{*}{4} & sandstone-2 & $k_{l}$ & 5.42 & $\begin{array}{l}17.14 ; 15.95 \\
18.04 ; 19.07\end{array}$ & $\begin{array}{c}18.44 ; 21.37 ; 22.03 \\
20.67 ; 21.55\end{array}$ & $\begin{array}{l}21.40 \\
\pm 0.56 \\
\end{array}$ \\
\hline & indenter-30 & $k_{u}$ & 21.57 & $\begin{array}{l}21.75 ; 23.55 \\
22.37 ; 25.65\end{array}$ & $\begin{array}{c}23.95 ; 24.24 ; 24.25 \\
26.35 ; 25.36\end{array}$ & $\begin{array}{l}25.05 \\
\pm 1.01\end{array}$ \\
\hline \multirow{2}{*}{5} & sandstone- 2 & $k_{l}$ & 3.03 & $\begin{array}{l}16.81 ; 26.18 \\
29.14 ; 30.77\end{array}$ & $\begin{array}{c}30.96 ; 31.69 ; 34.11 \\
32.98 ; 35.88\end{array}$ & $\begin{array}{l}32.73 \\
\pm 2.00\end{array}$ \\
\hline & indenter-45 & $k_{u}$ & 37.88 & $\begin{array}{l}37.80 ; 39.66 ; \\
38.10 ; 40.61\end{array}$ & $\begin{array}{c}40.00 ; 43.97 ; 37.78 \\
40.25 ; 41.23\end{array}$ & $\begin{array}{l}40.64 \\
\pm 2.01\end{array}$ \\
\hline 6 & sandstone- 2 & $k_{l}$ & 5.16 & $\begin{array}{l}19.12 ; 19.67 ; \\
18.79 ; 21.59\end{array}$ & $\begin{array}{c}21.95 ; 22.32 ; 21.94 ; \\
22.80 ; 21.58\end{array}$ & $\begin{array}{l}22.03 \\
\pm 0.47\end{array}$ \\
\hline 0 & indenter-60 & $k_{u}$ & 25.87 & $\begin{array}{l}22.96 ; 31.98 ; \\
28.92 ; 26.16\end{array}$ & $\begin{array}{c}27.38 ; 28.78 ; 29.67 \\
24.77 ; 26.08\end{array}$ & $\begin{array}{l}27.14 \\
\pm 1.84 \\
\end{array}$ \\
\hline
\end{tabular}

From the time series of both the contact force and the indenter acceleration, the impacts between the indenter and the rock can be observed clearly.

\subsection{Influence of rock sample rotation}

According to the experimental apparatus introduced in subsection 2.1, in addition to the excitation frequency and amplitude of the shaker, the pneumatic pressure on the actuator, the rotary speed of the DC electrical motor can also be adjusted. The first three parameters control the axial vibration of the indenter assembly to mimic the percussive drilling; while the last parameter determines the rotary speed of the rock to mimic the rotary drilling. Hence, in this experiment, both the percussive and rotary motions can be coupled to mimic the rotary-percussive drilling. By this way, the dynamics of the indenter in both the pure percussive drilling and the rotary-percussive drilling can be compared, see Fig. 2.5. In 
(a)

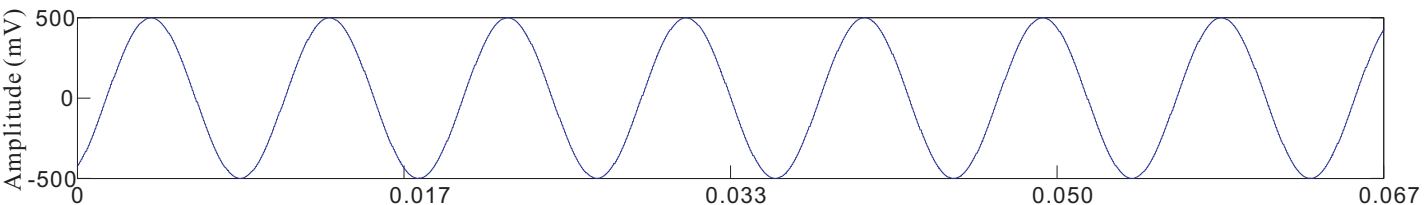

(b)

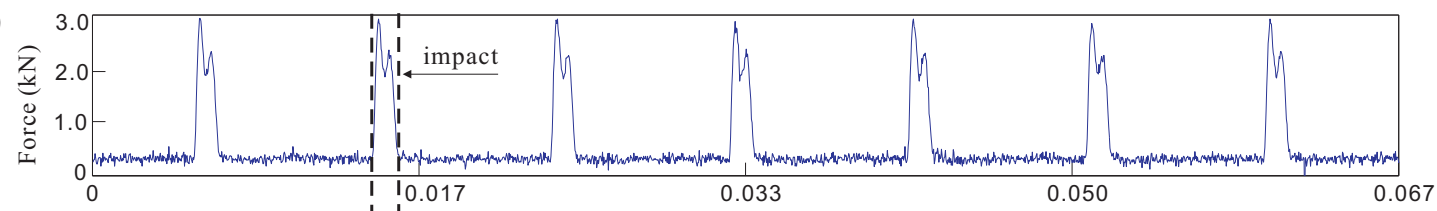

(c)

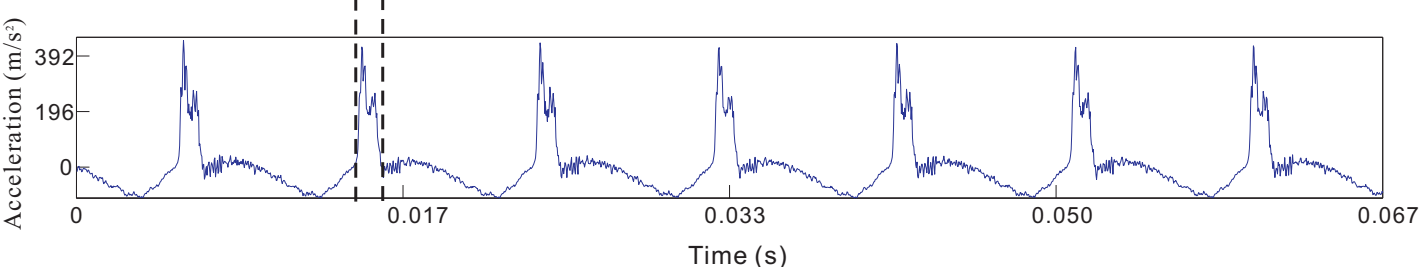

Figure 2.4: Experimental time series for the sandstone2-indenter30 combination. Subplot (a) shows the input excitation signal, subplot (b) shows the contact force, and subplot (c) shows the indenter acceleration.

subplots (a) and (b) for $\Omega=50 \mathrm{~Hz}$, the same period-one four-impact motions (which is written as P-1-I-4, and such simplification rule will be used in the rest of the paper) are observed. When the excitation frequency is increased to $100 \mathrm{~Hz}$, the same P-2-I-2 motions are explored, see subplots (c) and (d). Further increasing the excitation frequency to $150 \mathrm{~Hz}$, the recorded time series are shown in subplots (e) and (f), and the same P-1-I-1 motions are observed. Therefore, the axial vibration condition of the indenter is explored to be independent to the rotary motion.

In addition, slight differences of the acceleration peaks between the pure percussive drilling and the rotary-percussive drilling are also observed. This is due to the influence of the rotary motion. Specifically, the contact zone on the rock will be compressed by the repeated impacts of the indenter, which stiffens the contacted rock surface to induce stronger impacts, and thus increases the height of the acceleration peak. However, for the case of the rotary-percussive drilling, except the repeated impacts of the indenter, the rock surface is also grinded by the indenter due to the rock rotation, and the rock fragments are created and then removed from the rock surface; therefore, the rock surface always keeps fresh without sufficient compression; hence, its acceleration peak is relatively lower than that of the pure percussive drilling.

Base on the above analysis, the process of the quasi-static rock indentation test, which is introduced 
in subsection 2.2, is closer to the pure percussive drilling, since neither the rotation of the rock nor that of the indenter was considered during the quasi-static tests. Moreover, the axial vibration condition of the indenter has been verified to be independent to the rock rotation; hence, the dynamics of the indenter explored in the percussive drilling can also be applied to understand its axial vibration during rotary-percussive drilling. Therefore, in the following experimental investigations, the rock part in this experimental rig will keep static without rotation, and the dynamics of percussive drilling rather than rotary-percussive drilling will be discussed in detail.
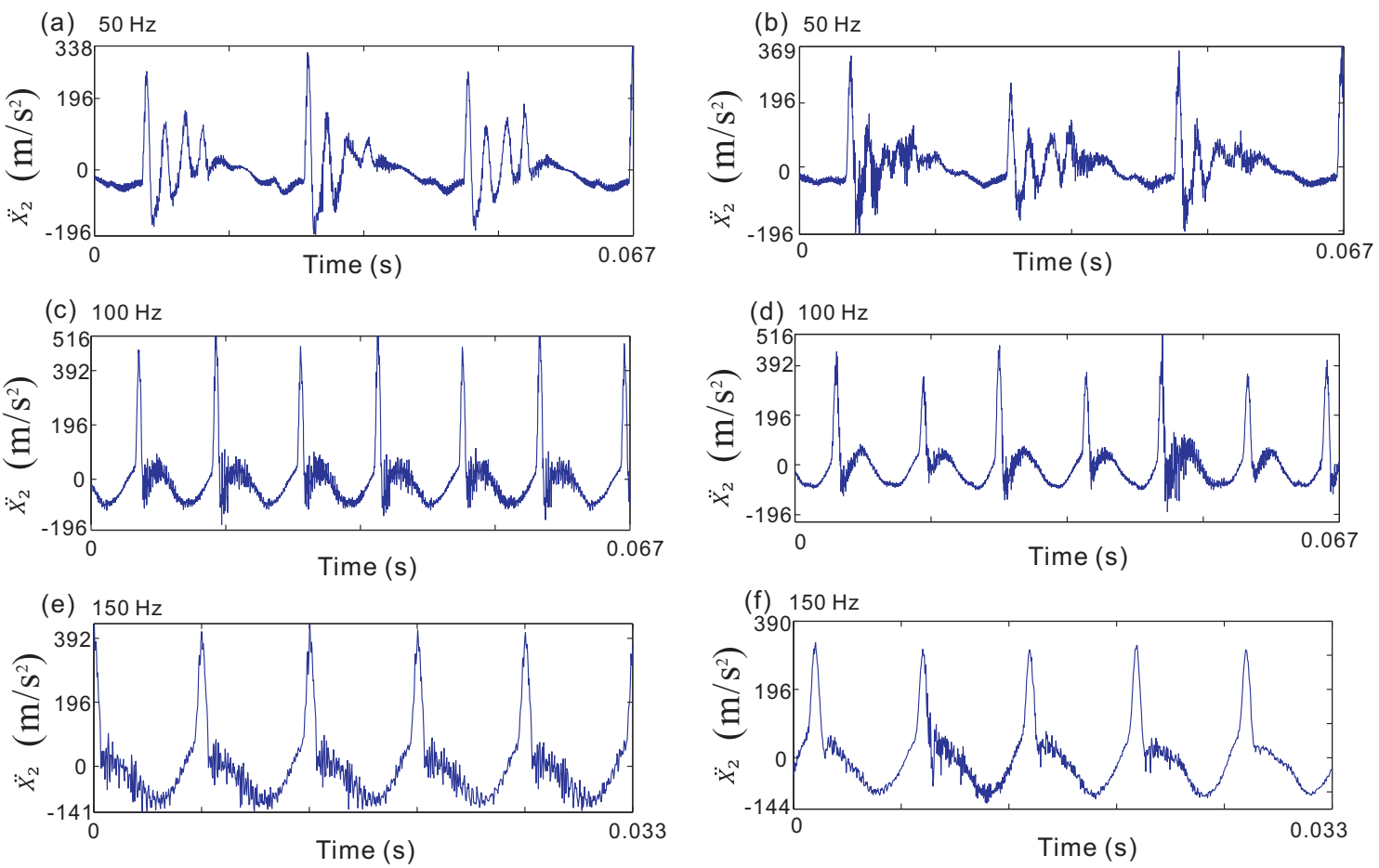

Figure 2.5: Experimental time series for the sandstone2-indenter30 combination under both the pure percussive and rotarypercussive drilling tests. The excitation voltage amplitude was $500 \mathrm{mV}$, the pneumatic pressure applied on the actuator was $1.0 \mathrm{bar}$, and the excitation frequency was set as $50 \mathrm{~Hz}, 100 \mathrm{~Hz}$, and $150 \mathrm{~Hz}$, respectively. Subplots (a),(c),(e) show the experimental measurements for the pure percussive drilling; while subplots (b),(d),(f) show the corresponding measurements for the rotary-percussive drilling with rock rotation speed $100 \mathrm{rpm}$.

\section{Mathematical modelling}

Based on the built experimental apparatus, a corresponding physical model for percussive drilling is presented in Fig. 3.1. Both to simplify the mathematical modelling and to reflect the basic characteristics associated with the vibro-impact system, three assumptions are considered in advance [41]. (1) Comparing 


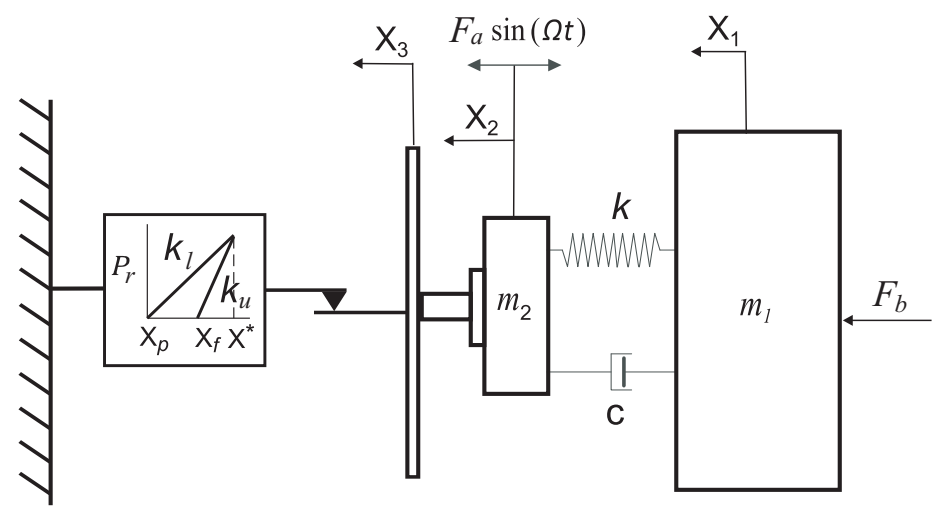

Figure 3.1: Physical model of a percussive drilling system. Static force $F_{b}$ is acted on mass $m_{1}$; mass $m_{2}$ is subjected to a harmonic excitation force amplitude $F_{a}$ with angular velocity $\Omega . m_{1}$ and $m_{2}$ are connected by a structure spring $k$ and a structure damper $c$ in parallel. The displacements of $m_{1}, m_{2}$, and the rock surface are denoted by $X_{1}$, $X_{2}$, and $X_{3}$, respectively. The rock part is modeled as Fig. 2.3 (c).

with the impacted media, the hardening treatment has increased the stiffness of the indenter considerably; thus, the indenter can be treated as rigid, and only the rock deforms during the vibro-impacts. (2) The force-penetration correlation obtained from the quasi-static rock indentation test is assumed to be valid to model the dynamic indenter-rock interaction, i.e., there is no rate dependence in the impact law. (3) The supplied air pressure inside the pneumatic cylinder is assumed to be constant throughout the whole experimental test. Under such circumstances, a bounded mathematical model can be written in a compact form [32] as

$$
\left\{\begin{array}{l}
p^{\prime}=v_{1}-P_{1} P_{2}\left(1-\frac{n_{l}(q-m)^{n_{l}-1}}{\kappa n_{u} q^{n_{u}-1}}\right) v_{2}, \\
v_{1}^{\prime}=\alpha b-\alpha \beta(p-q)-2 \alpha \xi\left(v_{1}-v_{2}\right) \\
q^{\prime}=v_{2}-P_{1} P_{2}\left(1-\frac{n_{l}(q-m)^{n_{l}-1}}{\kappa n_{u} q^{n_{u}-1}}\right) v_{2}, \\
v_{2}^{\prime}=a \sin (s)-\beta(q-p)-2 \xi\left(v_{2}-v_{1}\right)-P_{1} P_{2}(q-m)^{n_{l}}-P_{1}\left(1-P_{2}\right) P_{3} \kappa q^{n_{u}}, \\
r^{\prime}=P_{1} P_{2}\left(v_{2}-\left(1-\frac{n_{l}(q-m)^{n_{l}-1}}{\kappa n_{u} q^{n_{u}-1}}\right) v_{2}\right)+P_{1}\left(1-P_{2}\right) P_{3} v_{2}, \\
m^{\prime}=-P_{1} P_{2}\left(1-\frac{n_{l}(q-m)^{n_{l}-1}}{\kappa n_{u} q^{n_{u}-1}}\right) v_{2}+P_{1}\left(1-P_{2}\right) P_{3}\left(1-\frac{\kappa n_{u} q^{n_{u}-1}}{n_{l}(q-m)^{n_{l}-1}}\right) v_{2}, \\
s^{\prime}=\omega .
\end{array}\right.
$$

This system operates in any of the three modes [32, 42]: no contact, loading contact, and unloading 
contact, hence three Heaviside's functions are defined as

$$
\left\{\begin{array}{l}
P_{1}=H(q-m), \\
P_{2}=H\left(v_{2}\right), \\
P_{3}=H(q) .
\end{array}\right.
$$

In order to obtain the bounded mathematic model displayed in Eq. 3.1, four relative displacements [31] are defined to separate the bounded oscillation from drift as

$$
\left\{\begin{array}{l}
p=x_{1}-x_{f}, \\
q=x_{2}-x_{f}, \\
r=x_{3}-x_{f}, \\
m=x_{p}-x_{f} .
\end{array}\right.
$$

In Eq. 3.1, 3.2, and 3.3, the nondimensionalized variables and parameters of this system are listed as follows

$$
\begin{aligned}
& x_{1}=\frac{X_{1}}{\mu}, \quad x_{2}=\frac{X_{2}}{\mu}, \quad x_{3}=\frac{X_{3}}{\mu}, \quad x_{p}=\frac{X_{p}}{\mu}, \quad x_{f}=\frac{X_{f}}{\mu}, \\
& \tau=\Omega_{0} t, \quad \alpha=\frac{m_{2}}{m_{1}}, \quad \omega=\frac{\Omega}{\Omega_{0}}, \quad a=\frac{F_{a}}{m_{2} \mu \Omega_{0}^{2}}, \quad b=\frac{F_{b}}{m_{2} \mu \Omega_{0}^{2}}, \\
& \beta=\frac{k}{k_{l}} \mu^{1-n_{l}}, \quad \xi=\frac{c}{2 m_{2} \Omega_{0}}, \quad \kappa=\left(\frac{k_{u}}{k_{l}}\right) \mu^{n_{u}-n_{l}}, \quad \Omega_{0}^{2}=\frac{k_{l}}{m_{2}} \mu^{n_{l}-1},
\end{aligned}
$$

where $\mu$ is a reference distance, and $\Omega_{0}$ is the natural frequency. In addition, $x_{1}^{\prime}, v_{1}^{\prime}, x_{2}^{\prime}, v_{2}^{\prime}, x_{3}^{\prime}, s^{\prime}$ denote the differentiations of the corresponding variables with respect to the nondimensionalized time $\tau$. $n_{l}$ and $n_{2}$ are set to describe the nonlinearity of the rock-indenter interaction, since the rock stiffness is fitted linearly, $n_{l}=n_{2}=1$ in this paper. In addition, both the amplitude and frequency of excitation affect the force amplitude, $F_{a}$. According to the experimental calibration, their correlation can be expressed as

$$
F_{a}=(2.40 \Omega+876.19) \cdot A
$$


where $\Omega$ and $A$ are the input frequency (Hz) and amplitude (Volt) of excitation, respectively. The pneumatic pressure, $p$, provided to the actuator determines the static force, $F_{b}$, applied on the indenter. According to the experimental calibration, their correlation can be expressed as

$$
F_{b}=196.35 \cdot p
$$

Based on the developed mathematical model, a comprehensive numerical simulation for the sandstone2indenter30 combination was conducted, and the obtained results are shown in Fig. 3.2. For this simulation case, the excitation voltage amplitude was set as $450 \mathrm{mV}$, the pneumatic pressure was set as 1.0 bar, and the excitation frequency was swept from $50 \mathrm{~Hz}$ to $120 \mathrm{~Hz}$ with the interval $0.1 \mathrm{~Hz}$. Subplot (f) shows the whole bifurcation diagram, and subplot (e) is a blow-up of subplot (f) in the frequent range $90 \sim 110 \mathrm{~Hz}$. Subplots $(\mathrm{a}) \sim(\mathrm{d})$ and $(\mathrm{g}) \sim(\mathrm{j})$ display the vibro-impact vibrations of the indenter assembly. Specifically, the indenter starts vibration from a P-1-I-4 motion (see subplot $(\mathrm{g})$ ). As the increase of the excitation frequency, the period-one motion remains but the number of impacts per excitation period decreases to three times (see subplot (h)), or two times (see subplot (i)). When the frequency reaches $94.7 \mathrm{~Hz}$, a period-doubling bifurcation occurs, and the vibration condition transforms into a P-2-I-4 motion (see subplot (a)), which suddenly changes to a P-2-I-3 motion at $98.6 \mathrm{~Hz}$ with one impact missing for every two excitation periods (see subplot (b)). Based on the P-2-I-3 motion, another period-doubling bifurcation is observed at $102.0 \mathrm{~Hz}$, which triggers a P-4-I-6 motion (see subplot (c)). Subsequently, a chaotic motion (see subplot (d)) introduced by period-doubling cascade is explored when further increasing the excitation frequency. At last, the vibration condition jumps back to a P-1-I-1 motion at excitation frequency $109.8 \mathrm{~Hz}$ (see subplot $(\mathrm{j})$ ), and such a vibration condition lasts until the end of the considered parameter range. According to this bifurcation analysis, the whole variation trend of the vibration condition of the indenter has been understood, and the explored period-doubling bifurcations are expected to be observed in the following experiments. 
(a)

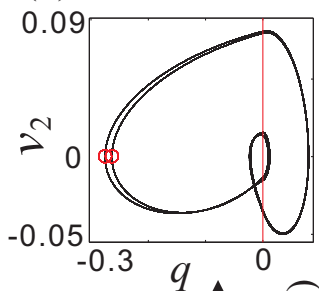

(b)

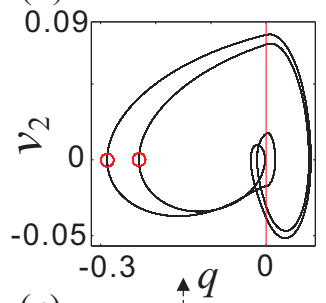

$(c)$

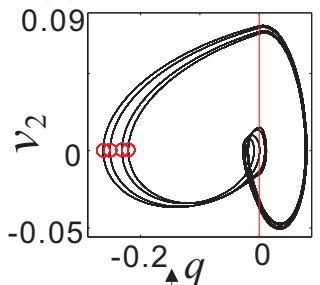

$(d)$

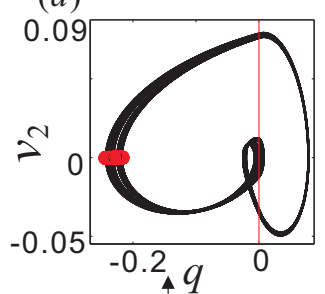

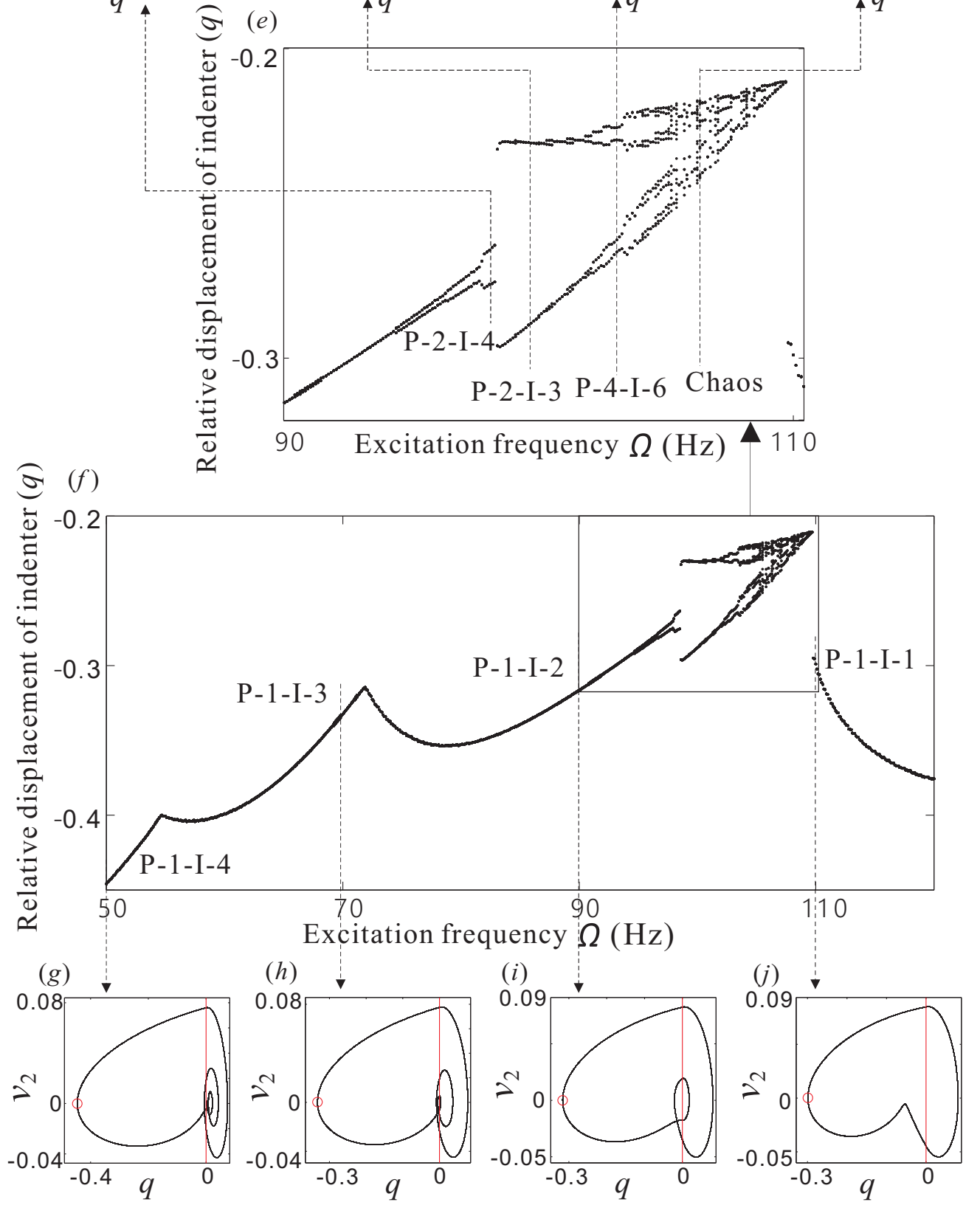

Figure 3.2: Numerical simulation for the sandstone2-indenter30 combination. The nondimensionalized parameters are $\alpha=0.0113, \beta=0.0032, \xi=0.1531, \kappa=1.1706, a=0.0209, b=0.0092, \omega=0.1176 \sim 0.2823$. Subplot (f) shows the obtained bifurcation diagram, and subplot (e) is a blow-up of subplot (f) for the frequency range 90 110Hz. Subplot (a), (b), (c), (d) show P-2-I-4, P-2-I-3, P-4-I-6, and chaotic motions, respectively. Subplot (g), (h), (i), (j) show P-1-I-4, P-1-I-3, P-1-I-2, and P-1-I-1 motions, respectively. 


\section{Comparisons between experimental measurements and numerical simulations}

This section presents bifurcation scenarios obtained numerically under variations of the control parameters including the frequency and amplitude of excitation, the pneumatic pressure, and also the different rock-indenter combinations. The numerical results are then compared with the corresponding experimental results which were collected by the built experimental apparatus. In particular, since the acceleration of the indenter, $\ddot{x_{2}}$, was measured directly by the accelerometer attached on the indenter assembly, the following investigations will use the acceleration of the indenter to construct bifurcation diagrams, so that the agreements and discrepancies between the numerical simulations and experimental measurements can be observed clearly.

\subsection{Frequency of excitation}

As displayed in Fig. 3.2, the variation of vibration conditions of the indenter and the period-doubling bifurcation scenarios have already been explored by increasing the excitation frequency in $50 \sim 120 \mathrm{~Hz}$. Hence, as a start, the excitation frequency was swept from $50 \mathrm{~Hz}$ to $120 \mathrm{~Hz}$ with an interval $10 \mathrm{~Hz}$ during the experimental tests, and the collected experimental measurements are compared with the numerical simulations in Fig. 4.1. Specifically, the axial vibration of the indenter varies from the P-1-I-4 motion (see subplots (b)-(d)) to the P-1-I-3 motion (see subplots (e)-(g)) when increasing the frequency from $50 \mathrm{~Hz}$ to $70 \mathrm{~Hz}$. As further increasing the frequency, the appearance of a period-doubling bifurcation induces period-two motions (see subplots (h)-(j)). Eventually, the vibration condition returns to a P-1-I-1 motion (see subplots $(\mathrm{k})-(\mathrm{m}))$ via a fold bifurcation.

Furthermore, from Fig. 4.1 to know, although the experimental signals are noisy for low acceleration, the main impacts can be identified clearly from the time series, and the agreements between the experimental measurements and the numerical simulations can still be demonstrated, since the correspondences of the vibration conditions between the numerical and experimental results are observed. Nevertheless, it should also be noted that, the experimental acceleration peaks of the indenter are slightly different from the ones obtained by numerical simulations. both the measurement error of the structure damping and the calculating error of the excitation force amplitude are the two potential reasons for such differences; 
however, these discrepancies still stay in an acceptance level.

\subsection{Amplitude of excitation}

In addition to the frequency of excitation, another key control parameter for vibro-impact motion is the amplitude of excitation which mainly determines the force of the axial impact. The experimental measurements and numerical simulations are compared by varying the amplitude of excitation in the range $300 \sim 600 \mathrm{mV}$, and the obtained results are shown in Fig. 4.2. It can be seen from the figure that periodone motions of the indenter were observed for the whole parameter ranges for both the experimental measurements and numerical simulations. However, in the low amplitude range (300 395mV), the P-1-I2 motion is obtained (see subplots (b)-(d)); while for the high excitation amplitude range (396 600mV), the P-1-I-1 motion is explored (see subplots (e)-(g), (h)-(j), and (k)-(m)).

Moreover, as seen in Fig. 4.2, Due to the decrease of the impact number, an obvious upward step of acceleration is observed in the bifurcation diagram, and the same phenomenon is also observed in Fig. 4.1 (a). The basic reason for such phenomenon is that, multiple impacts happened in one excitation period weakens the contact force of each impact, hence more energy is dissipated during the repeated loading and unloading process. Similarly, as demonstrated in [35], when comparing with other vibration conditions, the P-1-I-1 motion displayed the highest ROP; since for the P-1-I-1 motion, all the periodic excitation energy concentrates on only one impact, which induces the highest impact acceleration, and thus promote the ROP.

\subsection{Pneumatic pressure}

Subsequently, the experimental and numerical comparison by sweeping the pneumatic pressure in 0.6 1.8 bar is carried out, and the obtained results are shown in Fig. 4.3. According to the numerical simulation, a period-doubling bifurcation is detected at $p=0.63$ bar, and the period-two vibrations last until $p=0.72$ bar where an inverse period-doubling bifurcation appears. The experimental verification of the period-two motion was tested at $p=0.70$ bar, the measured time series is shown in subplot (b), which is indeed a period-two motion. Passing through the region of period-two vibrations, the vibration condition enters into period-one motions. As the further increase of the pneumatic pressure, the impact 


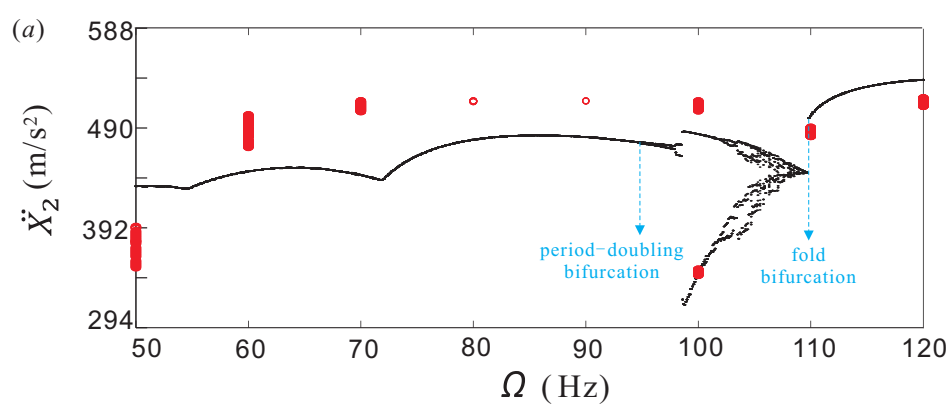

(b) $50 \mathrm{~Hz}$

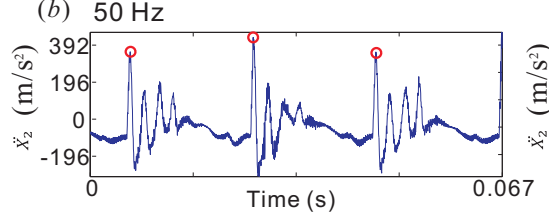

(e) $70 \mathrm{~Hz}$

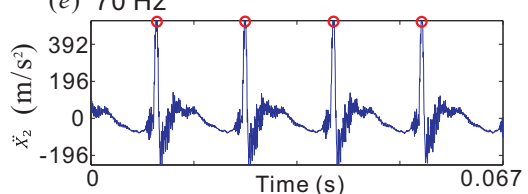

(h) $100 \mathrm{~Hz}$

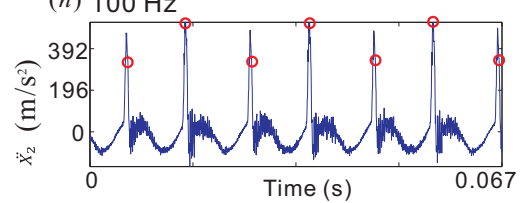

(k) $120 \mathrm{~Hz}$

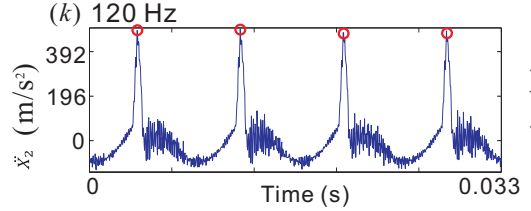

(c) $50 \mathrm{~Hz}$

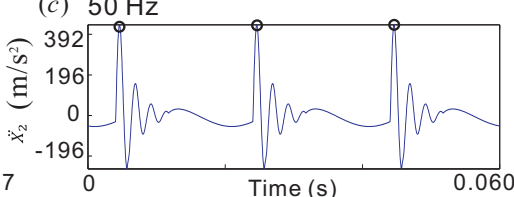

(f) $70 \mathrm{~Hz}$

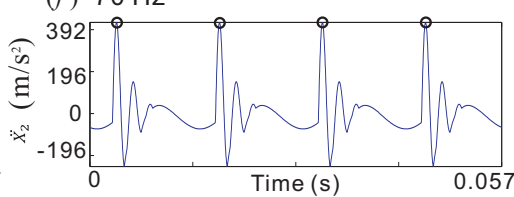

(i) $100 \mathrm{~Hz}$
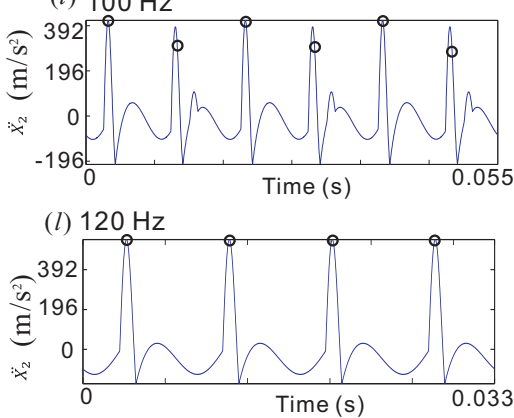

(d) $50 \mathrm{~Hz}$

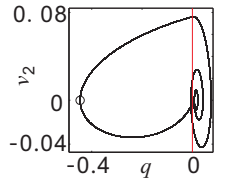

(g) $70 \mathrm{~Hz}$

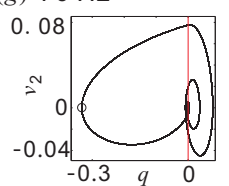

(j) $100 \mathrm{~Hz}$

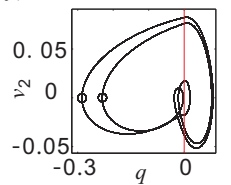

(m) $120 \mathrm{~Hz}$

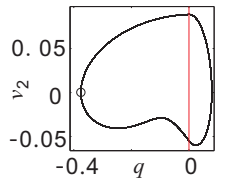

Figure 4.1: Comparisons of experimental and numerical results for the sandstone2-indenter30 combination with the excitation voltage amplitude $450 \mathrm{mV}$, pneumatic pressure $1.0 \mathrm{bar}$, and excitation frequency range $50 \sim 120 \mathrm{~Hz}$. Subplot (a) shows the bifurcation diagram in the Frequency - Acceleration space, the red points are obtained from experiments, and the black dots are obtained from simulations. Subplots (b), (e), (h), (k) show the experimental time series for frequencies $50 \mathrm{~Hz}, 70 \mathrm{~Hz}, 100 \mathrm{~Hz}$, and $120 \mathrm{~Hz}$, respectively. Their corresponding numerical time series and phase portraits are displayed in subplots (c), (f), (i), (l), and subplots (d), (g), (j), (m), respectively. 


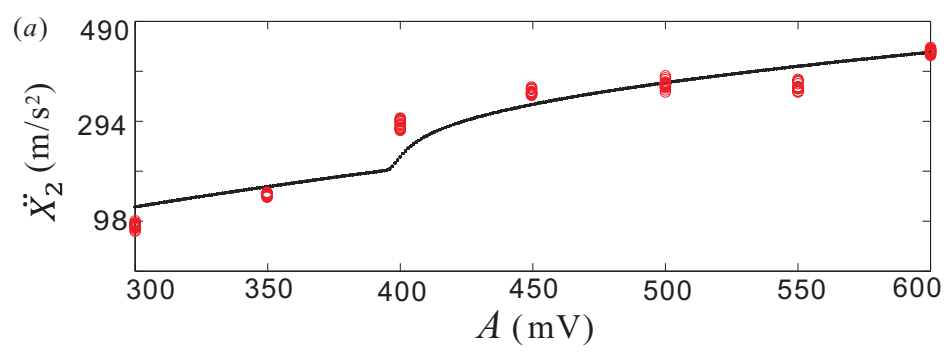

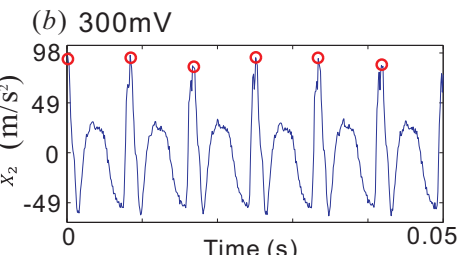
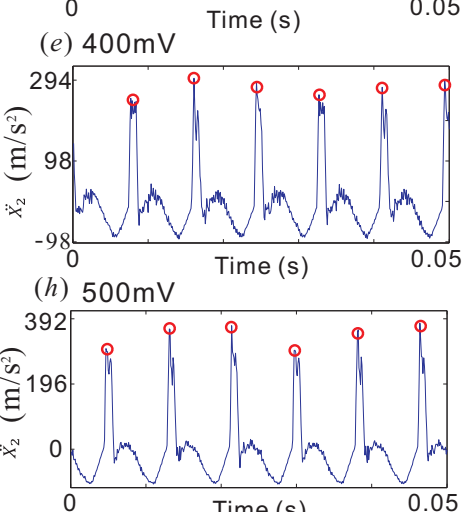

(k) $600 \mathrm{mV}$

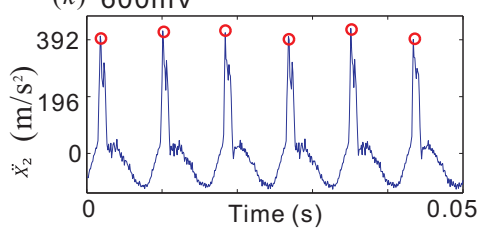

(c) $300 \mathrm{mV}$

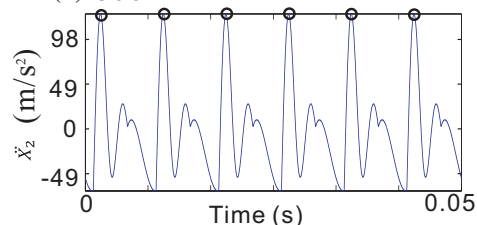

(f) $400 \mathrm{mV}$
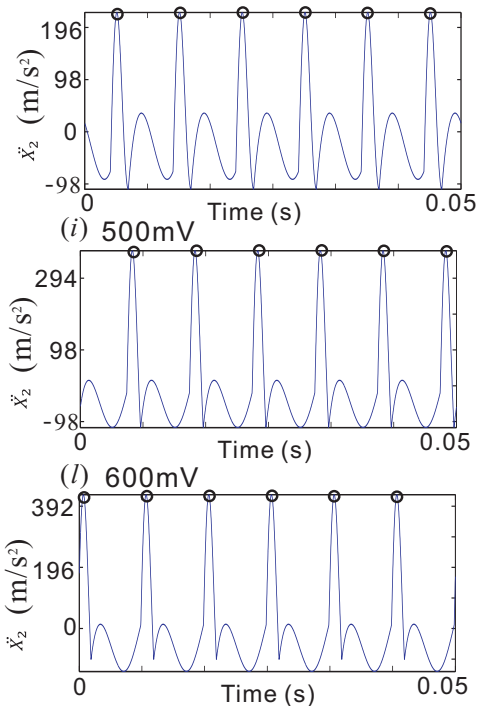

(d) $300 \mathrm{mV}$

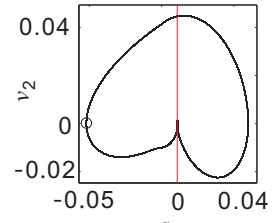

(g) $400 \mathrm{mV} q$

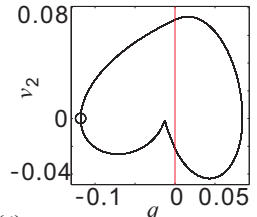

(j) $500 \mathrm{mV}^{q}$

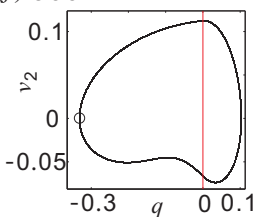

(m) $600 \mathrm{mV}$

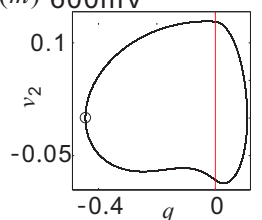

Figure 4.2: Comparisons of experimental and numerical results for the sandstone1-indenter45 combination with pneumatic pressure 1.0 bar, excitation frequency $120 \mathrm{~Hz}$, and excitation voltage amplitude $300 \sim 600 \mathrm{mV}$. Subplot (a) shows the bifurcation diagram in the Amplitude - Acceleration space, the red points are obtained from experiments, and the black dots are obtained from simulations. Subplots (b), (e), (h), (k) show the experimental time series for amplitudes 300mV, $400 \mathrm{mV}, 500 \mathrm{mV}$, and $600 \mathrm{mV}$, respectively. Their corresponding numerical time series and phase portraits are displayed in subplots (c), (f), (i), (l), and subplots (d), (g), (j), (m), respectively. 
number keeps increasing, from P-1-I-2 (see subplot (e)-(g)), P-1-I-3 (see subplot (h)-(j)), to multiple impacts in one excitation period (see subplot $(\mathrm{k})-(\mathrm{m})$ ), and the corresponding experimental results also display such a trend.

Meanwhile, in Fig. 4.3, it deserves to note that the increase of the pneumatic pressure, i.e., the static force, triggers the increase of the impacts; hence, the axial acceleration of the indenter decreases gradually; moreover, the chattering phenomenon was observed during the experiments when the applied pneumatic pressure reached 1.4 bar (see subplot $(\mathrm{h})$ and $(\mathrm{k})$ ). Due to the appearance of chattering, the differences between the main impact peak and other secondary impact peaks shrink sharply, and the main impact peak can not even be distinguished. This phenomenon indicates that the vibro-impact motion (or the rebound of the indenter) can be restricted by the high pneumatic pressure; therefore, if one single powerful impact rather than a series of weak contacts is desired for the actual percussive drilling, the high pneumatic pressure should be avoided.

\subsection{Rock stiffness}

Different from the three control parameters discussed above, the stiffness parameters for a rockindenter combination consist of loading stiffness and unloading stiffness, $\left(k_{l}, k_{u}\right)$. Hence, once the tested rock-indenter combination is replaced, both the loading and unloading stiffnesses will be changed simultaneously. Since there are two branching parameters need to be considered, a three-dimension $\left(k_{l}-k_{u}-\ddot{x_{2}}\right)$ diagram is depicted in Fig. 4.4 (a) to show the bifurcation scenarios. Meanwhile, a projection of subplot (a) in the $k_{l}-\ddot{x_{2}}$ space is also shown in subplot (b). As listed in Table 2.2, six rock-indenter combinations were measured via the rock indentation test; hence, six groups of dynamic tests were conducted by using this experimental apparatus. The collected experimental time series are displayed in Fig. 4.4 (c), (f), (i), (l), (o), (r), respectively. From these subplots, the axial vibration of the indenter is explored to be varied from period-one motions to period-two motions via a period-doubling bifurcation, and then the vibration condition returns to period-one motions via an inverse period-doubling bifurcation.

In Fig. 4.4, the agreements of the vibration conditions of the indenter between the experiments and simulations are further demonstrated; however, the discrepancies of the acceleration peaks between 


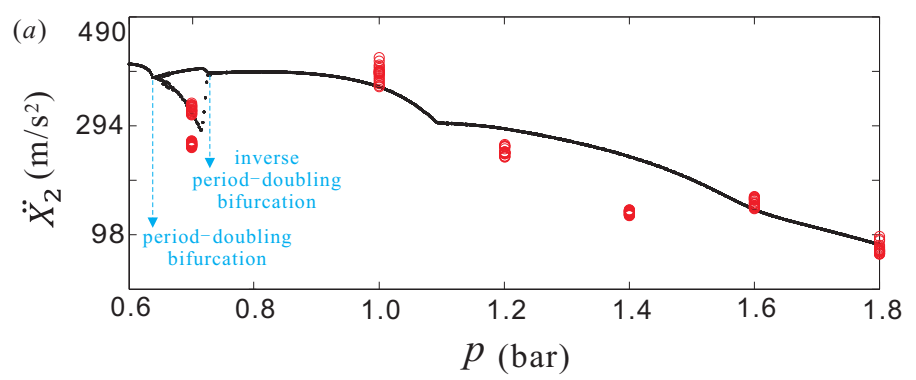

(b) $0.7 \mathrm{bar}$

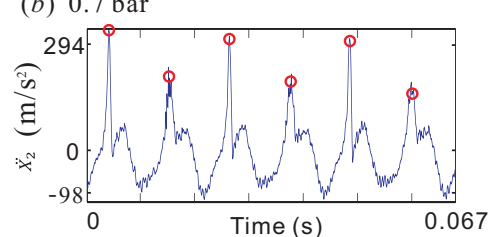

(e) $1.0 \mathrm{bar}$

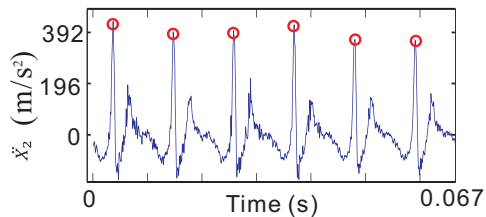

(h) $1.4 \mathrm{bar}$

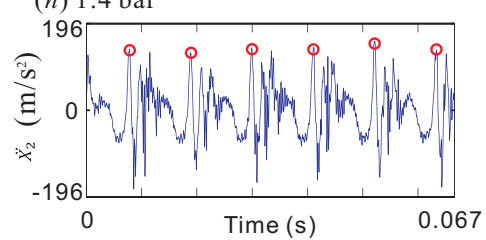

(k) $1.8 \mathrm{bar}$

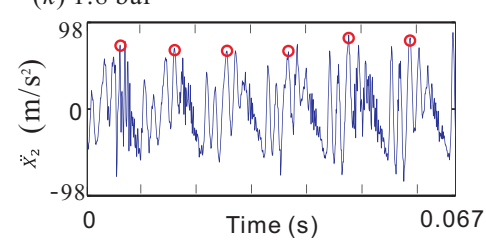

(c) $0.7 \mathrm{bar}$

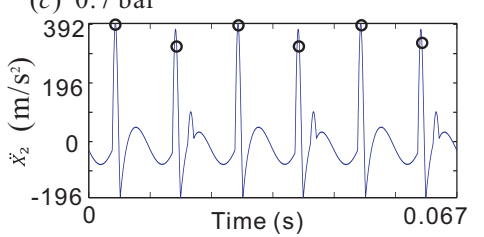

(f) $1.0 \mathrm{bar}$

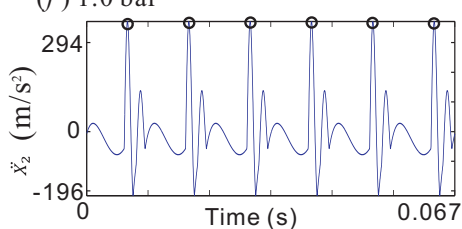

(i) $1.4 \mathrm{bar}$

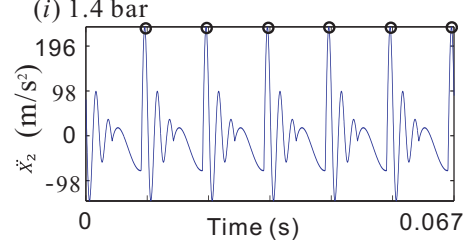

(l) $1.8 \mathrm{bar}$

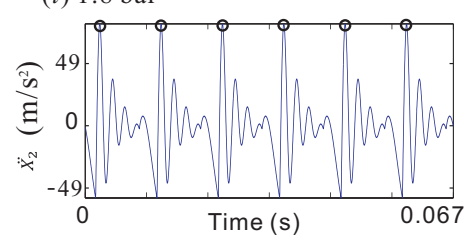

(d) $0.7 \mathrm{bar}$

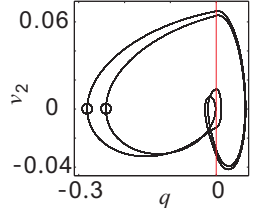

(g) $1.0 \mathrm{bar}$

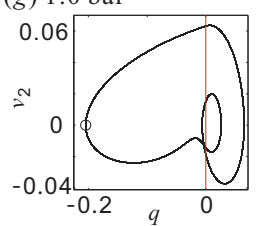

(j) $1.4 \mathrm{bar}$

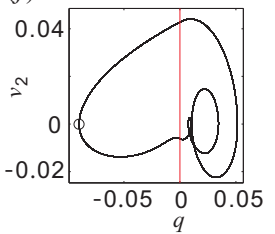

(m) 1.8 bar

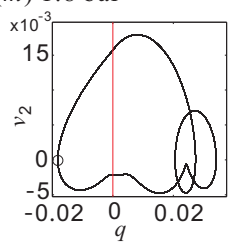

Figure 4.3: Comparisons of experimental and numerical results for the sandstone2-indenter30 combination with excitation frequency $90 \mathrm{~Hz}$, excitation voltage amplitude $450 \mathrm{mV}$, and the range of pneumatic pressure $0.6 \sim 1.8$ bar. Subplot (a) shows the bifurcation diagram in the Pressure - Acceleration space, the red points are obtained from experiments, and the black dots are obtained from simulations. Subplots (b), (e), (h), (k) show the experimental time series for pneumatic pressures 0.7 bar, 1 bar, 1.4 bar, and 1.8 bar, respectively. Their corresponding numerical time series and phase portraits are displayed in subplots (c), (f), (i), (l), and subplots (d), (g), (j), (m), respectively. 
the experiments and simulations are noticed again for the stiffness cases about sandstone1 (comparing subplots (c) and (d), (f) and (g), (i) and (j), respectively). Except the two reasons discussed in Subsection 4.1, another possible reason may come from the linearly fitted force-penetration correlation, which is expected to be more suitable for describing the deformation of hard rocks under impacts rather than that of soft rocks or rocks with high ductility; since the discrepancies of the acceleration peaks for sandstone2, whose Young's modulus is $28.51 \mathrm{GPa}$, are much smaller than that of sandstone1, whose Young's modulus is $4.80 \mathrm{GPa}$.

\section{Concluding remarks and future work}

This paper presents an experimental verification of a percussive drilling system which has been numerically studied in $[32,40,42]$. The developed experimental rig consists of an actuator-shaker-indenter part and a motor-pulley-rock part. The actuator-shaker-indenter part provided the vibro-impact motion of the indenter to mimic the percussive drilling, which was controlled by the frequency and amplitude of excitation, and also the pneumatic pressure. For the sake of simplifying the structure of the experimental rig, rotation of rock rather than rotation of indenter was designed, and a motor-pulley-rock part took the responsibility to hold the impacted rock, and to rotate the rock if the rotary drilling needs to be considered. Base on such an experimental design, the rotary-percussive coupling effects can be tested experimentally. As shown in Fig. 2.5, according to the comparison of the dynamics of the indenter between the pure percussive drilling and the rotary-percussive drilling, the axial vibration condition of the indenter was verified to be independent to the rock rotation; hence, the dynamics of the indenter explored in the percussive drilling can also be applied to understand its axial vibration during rotary-percussive drilling.

Subsequently, the dynamic behaviors of the percussive drilling system under different control parameters and different rock-indenter combinations were investigated comprehensively. The experimental measurements and the numerical simulations were compared systematically. In the given parameter ranges, the vibration of the indenter mainly switched between period-one motions and period-two motions, which were triggered by period-doubling or inverse period-doubling bifurcations, see Figs. 4.1, 4.3, 

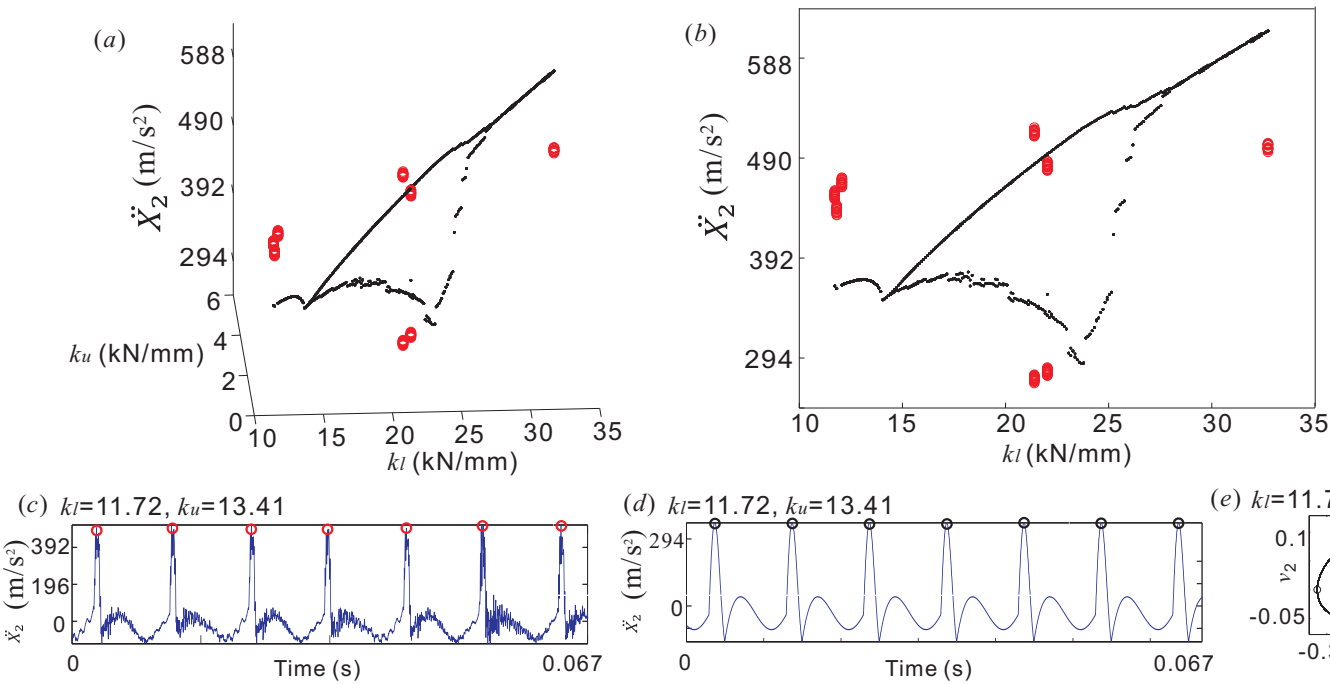

(e) $k l=11.72, \mathrm{k}_{u}=13.41$
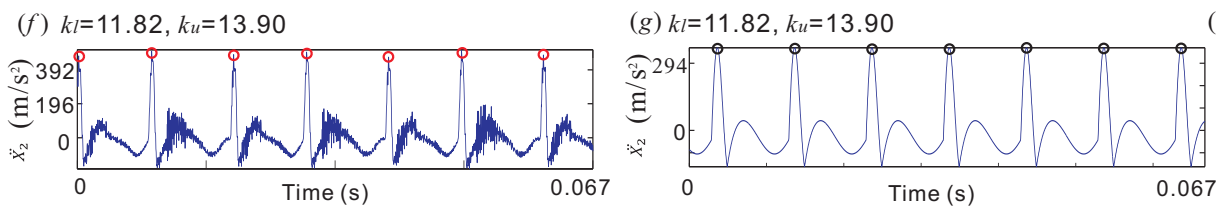

(h) $k l=11.82, k u=13.90$
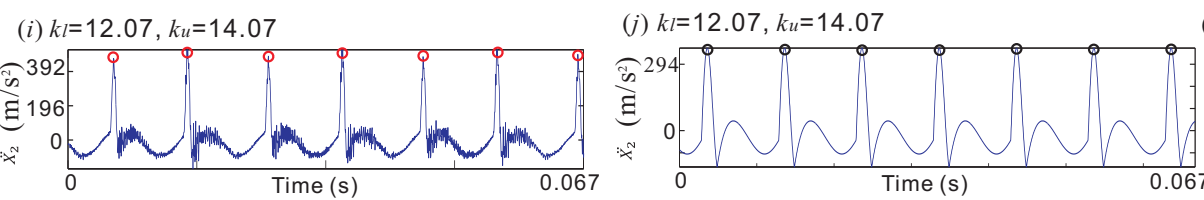

(k) $k l=12.07, k_{u}=14.07$
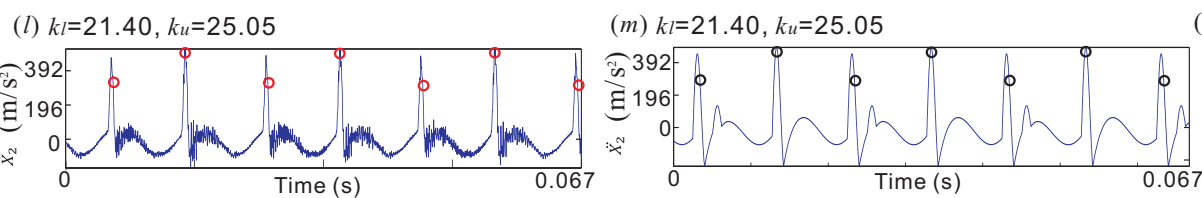

(n) $k l=21.40, k u=25.05$

(o) $k l=22.03, k u=27.14$
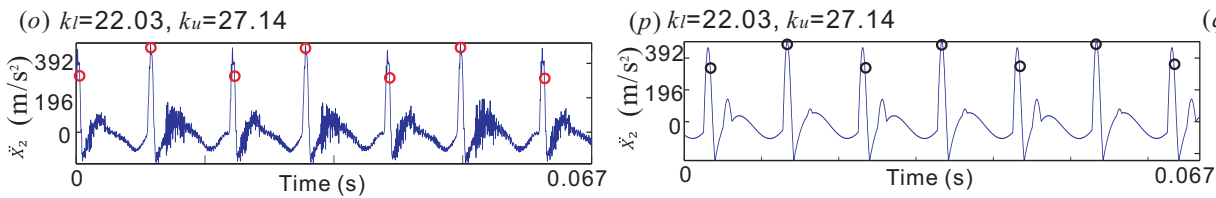

(q) $k l=22.03, k u=27.14$

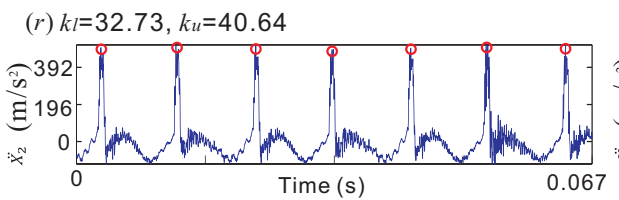

(s) $k l=32.73, k u=40.64$
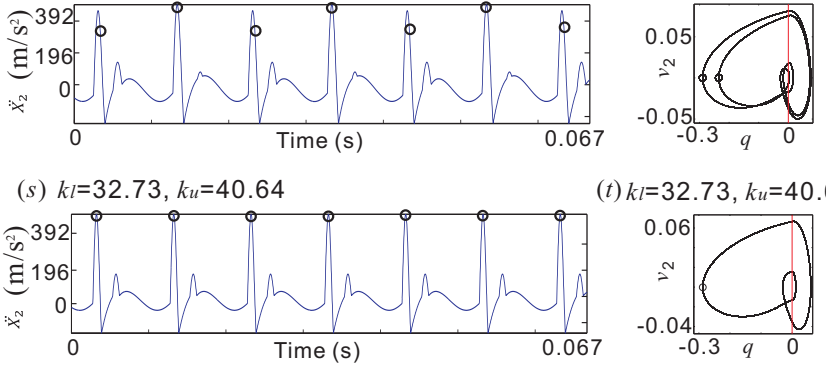

(t) $k l=32.73, k_{u}=40.64$

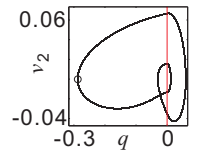

Figure 4.4: Comparisons of experimental and numerical results for different rock-indenter combinations. Subplot (a) shows the bifurcation diagram in $k_{l}-k_{u}-\ddot{x_{2}}$ space, while subplot (b) is the projection of subplot (a) in $k_{l}-\ddot{x_{2}}$ space. In these two subplots, the red points are obtained from experiments, and the black points are obtained from simulations. Subplots (c), (f), (i), (l), (o), (r) show the experimental results for the six stiffness combinations listed in Table 2.2 with excitation frequency $100 \mathrm{~Hz}$, excitation voltage amplitude $450 \mathrm{mV}$, and pneumatic pressure 1.0 bar. Their corresponding numerical time series and phase portraits are displayed in subplots (d)-(s) and subplots (e)-(t), respectively. 
and 4.4. Although period-one motions was the main dynamic responses in the considered parameter ranges, the impact numbers in one excitation period varied as parameters. The impact number per period directly affected the achieved maximal impact acceleration of the indenter, which was reflected by a series of acceleration steps in the bifurcation diagrams, see Figures 4.1, 4.2, 4.3. These acceleration steps indicated the variation of the impact force. Specifically, since more energy was dissipated during the repeated loading and unloading process, multi-impact per excitation period weakened the contact force of each impact, and thus lowered its capacity of breaking rocks. Therefore, in order to obtain the powerful impact, the ideal vibration condition of indenter is the P-1-I-1 motion. Under such circumstances, for drilling hard rocks, the high excitation frequency and amplitude are suggested; however, the high pneumatic pressure should be avoided since it can trigger the chattering of indenter, see Fig. 4.3 (h) and $(\mathrm{k})$.

In addition, during the comparisons of experimental measurements and numerical simulations, some discrepancies were observed, which could be explained by the measurement error of the structure damping and the calculating error of the excitation force amplitude. Meanwhile, the linearly fitted forcepenetration correlations could also induce the error, since the linearly fitted model was expected to be more suitable for describing the deformation of hard rocks under impacts rather than soft rocks or rocks with high ductility. However, all the errors stayed in acceptable levels; moreover, the agreements of the vibration conditions of indenter between experiments and simulations were always remained. Therefore, it can be concluded that the proposed mathematical model is capable of predicting the dynamic behaviors of percussive drilling systems.

For the future work, both the percussion and the rotation of indenter need to be effectively coupled to develop a completed mathematical model for simulating rotary-percussive drilling systems. This coupled model is expected to be significant for further studying the dynamics of the actual rotary-percussive drilling systems. Correspondingly, the built experimental apparatus will also be further improved so that it is capable to verify the dynamics of the rotary-percussive drilling systems experimentally. In addition, the interplay among the three control parameters, including the excitation frequency and amplitude, and pneumatic pressure, deserves further study on establishing a space of control parameters to delimit the 
boundary curves for the P-1-I-1 motion, by this way, the ideal vibration condition with high efficiency can be effectively maintained during the whole drilling process.

\section{Acknowledgements}

This paper is supported by National Natural Science Foundation of China (No. 51904018), Beijing Municipal Natural Science Foundation (No. 3204049), Fundamental Research Funds for the Central Universities (No. FRF-TP-18-054A1), and Interdisciplinary Research Project for Young Teachers of USTB (Fundamental Research Funds for the Central Universities) (No. FRF-IDRY-19-006).

\section{References}

[1] S. Powell, A. Garcia, H. Barocio, A. Alonso, "Percussion drilling system combined with hybrid PDC bit increases ROP and interval drilled on Taoudenni basin well in Mauritania," in SPE/IADC Drilling Conference and Exhibition, (London, England, UK), 2015.

[2] W.A. Hustrulid, C. Fairhurst, "A theoretical and experimental study of the percussive drilling of rock. Part I-theory of percussive drilling," International Journal of Rock Mechanics and Mining Science 83 Geomechanics Abstracts, vol. 8, no. 4, pp. 311-333, 1971.

[3] W.A. Hustrulid, C. Fairhurst, "A theoretical and experimental study of the percussive drilling of rock. Part II-force-penetration and specific energy determinations," International Journal of Rock Mechanics and Mining Science E Geomechanics Abstracts, vol. 8, no. 4, pp. 335-340, 1971.

[4] W.A. Hustrulid, C. Fairhurst, "A theoretical and experimental study of the percussive drilling of rock. Part III-experimental verification of the mathematical theory," International Journal of Rock Mechanics and Mining Science \& Geomechanics Abstracts, vol. 9, no. 3, pp. 417-429, 1972.

[5] W.A. Hustrulid, C. Fairhurst, "A theoretical and experimental study of the percussive drilling of rock. Part IV-application of the model to actual percussion drilling," International Journal of Rock Mechanics and Mining Science \& Geomechanics Abstracts, vol. 9, no. 3, pp. 431-442, 1972. 
[6] B. Lundberg, "Energy transfer in percussive rock destruction-I: comparison of percussive methods," International Journal of Rock Mechanics and Mining Science 83 Geomechanics Abstracts, vol. 10, no. 5, pp. 381-399, 1973.

[7] B. Lundberg, "Energy transfer in percussive rock destruction-II: supplement on hammer drilling," International Journal of Rock Mechanics and Mining Science \&3 Geomechanics Abstracts, vol. 10, no. 5, pp. 401-419, 1973.

[8] B. Lundberg, "Energy transfer in percussive rock destruction-III: stress wave transmission through joints," International Journal of Rock Mechanics and Mining Science 83 Geomechanics Abstracts, vol. 10, no. 5, pp. 421-435, 1973.

[9] A.T. Kiselev, Y.A. Melamed, "Perspectives of the rotary-percussion drilling development with highfrequency hydro-hammers with low flow rates," in High School: Geology and Prospecting, pp. 85-94, 1984.

[10] Y. Melamed, A. Kiselev, M. Gelfgat, D. Dreesen, J. Blacic, "Hydraulic hammer drilling technology: Developments and capabilities," Journal of Energy Resources Technology, vol. 122, pp. 1-7, 2000.

[11] L.F.P. Franca, H.I. Weber, "Experimental and numerical study of a new resonance hammer drilling model with drift," Chaos, Solitons \& Fractals, vol. 21, pp. 789-801, 2004.

[12] N. Neumann, T. Sattel, "Set-oriented numerical analysis of a vibro-impact drilling system with several contact interfaces," Journal of Sound and Vibration, vol. 308, pp. 831-844, 2007.

[13] C. Potthast, J. Twiefel, J. Wallaschek, "Modelling approaches for an ultrasonic percussion drill," Journal of Sound and Vibration, vol. 308, pp. 405-417, 2007.

[14] Y. Kovalyshen, "Self-excited axial vibrations of a drilling assembly: modeling and experimental investigation," in 47th US Rock Mechanics/Geomechanics Symposium, (San Francisco, CA, USA), 2013. 
[15] F. Derdour, M. Kezzar, L. Khochmane, "Optimization of penetration rate in rotary percussive drilling using two techniques: Taguchi analysis and response surface methodology (RMS)," Power Technology, vol. 339, pp. 846-853, 2018.

[16] Z. Ji, H. Shi, G. Li, H. Song, "Improved drifting oscillator model for dynamical bit-rock interaction in percussive drilling under high-temperature condition," Journal of Petroleum Science and Engineering, vol. 186, 2020.

[17] L.F.P. Franca, "A bit-rock interaction model for rotary-percussive drilling," International Journal of Rock Mechanics 83 Mining Sciences, vol. 48, pp. 827-835, 2011.

[18] G. Han, M.S. Bruno, M.B. Dusseault, "Dynamically modelling rock failure in percussion drilling," in Symposium on Rock Mechanics (USRMS), (Anchorage, Alaska), 2005.

[19] G. Han, M.S. Bruno, "Percussion drilling: from lab tests to dynamic modeling," in International Oil E3 Gas Conference and Exhibition in China, (Beijing, China), 2006.

[20] G. Han, M.S. Bruno, T. Grant, "Lab investigations of percussion drilling: from single impact to full scale fluid hammer," in The 41st U.S. Symposium on Rock Mechanics (USRMS), (Golden, Colorado), 2006.

[21] G. Dong, P. Chen, "3D Numerical Simulation and Experiment Validation of Dynamic Damage Characteristics of Anisotropic Shale for Percussive-Rotary Drilling with a Full-Scale PDC Bit," Energies, vol. 11, no. 6, 2018.

[22] F.F. Real, A. Batou, T.G. Ritto, C. Desceliers, R.R. Aguiar, "Hysteretic bit/rock interaction model to analyze the torsional dynamics of a drill string," Mechanical Systems and Signal Processing, vol. 111, pp. 222-233, 2018.

[23] D.M. Lobo, T.G. Ritto, D.A. Castello, "A novel stochastic process to model the variation of rock strength in bit-rock interaction for the analysis of drill-string vibration," Mechanical Systems and Signal Processing, vol. 141, 2020. 
[24] M. Wiercigroch, Resonance enhanced drilling: Method and apparatus. Patent No. WO2007141550, 2007.

[25] M. Wiercigroch, M. Kapitaniak, V. Vaziri, N. Yari, Resonance Enhanced Rotary Drilling Actuator. Patent No. WO2016142537A3, 2016.

[26] M. Wiercigroch, V. Vaziri, M. Kapitaniak, "RED: Revolutionary Drilling Technology for Hard Rock Formations," in SPE/IADC Drilling Conference and Exhibition, (Hague, Netherlands), 2017.

[27] M. Liao, J. Ing, J. Páez Chávez, M. Wiercigroch, "Bifurcation techniques for stiffness identification of an impact oscillator," Commun. Nonlinear Sci. Numer. Simul., vol. 41, pp. 19-31, 2016.

[28] E. Pavlovskaia, M. Wiercigroch, C. Grebogi, "Modeling of an impact system with a drift," Physical Review E, vol. 64, no. 5, p. 056224, 2001.

[29] Q. Cao, M. Wiercigroch, E. Pavlovskaia, S. Yang, "Bifurcations and the penetrating rate analysis of a model for percussive drilling," Acta Mechanica Sinica, vol. 26, no. 3, pp. 467-475, 2010.

[30] E. Pavlovskaia, M. Wiercigroch, "Modelling of vibro-impact system driven by beat frequency," International Journal of Mechanical Sciences, vol. 45, no. 4, pp. 623-641, 2003.

[31] E. Pavlovskaia, M. Wiercigroch, "Analytical drift reconstruction for visco-elastic impact oscillator operating in periodic and chaotic regimes," Chaos, Solitons \&3 Fractals, vol. 19, pp. 151-161, 2004.

[32] M. Liao, Y. Su, Y. Zhou, "Oscillation reconstruction and bifurcation analysis of a drillbitrock vibroimpact system," International Journal of Bifurcation and Chaos, vol. 27, no. 1, p. 1750013, 2017.

[33] J. Páez Chávez, E. Pavlovskaia, M. Wiercigroch, "Bifurcation analysis of a piecewise-linear impact oscillator with drift," Nonlinear Dynamics, vol. 77, pp. 213-227, 2014.

[34] P. Thota, H. Dankowicz, "TC-HAT: A novel toolbox for the continuation of periodic trajectories in hybrid dynamical systems," SIAM J. Appl. Dyn. Sys., vol. 7, no. 4, pp. 1283-1322, 2008.

[35] E. Pavlovskaia, D.C. Hendry, M. Wiercigroch, "Modelling of high frequency vibro-impact drilling," International Journal of Mechanical Sciences, vol. 91, pp. 110-119, 2005. 
[36] Y. Liu, J. Paez Chavez, E. Pavlovskaia, M. Wiercigroch, "Analysis and control of the dynamic response of a higher order drifting oscillator," Proceedings, Royal Society of London, vol. 474, no. 2210, pp. 20170500, pp. 1-20, 2018.

[37] O.K. Ajibose, M. Wiercigroch, E. Pavlovskaia, A.R. Akisanya, "Global and local dynamics of drifting oscillator for different contact force models," International Journal of Nonlinear Mechanics, vol. 45, pp. $850-858,2010$.

[38] O.K. Ajibose, M. Wiercigroch, E. Pavlovskaia, A.R. Akisanya, G. Károlyi, "Drifting impact oscillator with a new model of the progression phase," Journal of Applied Mechanics, vol. 79, p. 061007, 2012.

[39] O.K. Ajibose, M. Wiercigroch, A.R. Akisanya, "Experimental studies of the resultant contact forces in drillbit-rock interaction," International Journal of Mechanical Sciences, vol. 91, pp. 3-11, 2015.

[40] M. Liao, J. Ing, M. Sayah, M. Wiercigroch, "Dynamic method of stiffness identification in impacting systems for percussive drilling applications," Mechanical Systems and Signal Processing, vol. 80, pp. 224-244, 2016.

[41] M. Sayah, Nonlinear time series analysis applied to resonance enhanced drilling. University of Aberdeen: PhD thesis, 2015.

[42] M. Liao, Y. Liu, J. Páez Chávez, A.S.E. Chong, M. Wiercigroch, M. Wiercigroch, "Dynamics of vibro-impact drilling with linear and nonlinear rock," International Journal of Mechanic Sciences, vol. 146, pp. 200-210, 2018. 